This item was submitted to Loughborough's Research Repository by the author.

Items in Figshare are protected by copyright, with all rights reserved, unless otherwise indicated.

\title{
Pure, white and deadly... expensive: a bitter sweetness in health care expenditure
}

\section{PLEASE CITE THE PUBLISHED VERSION}

http://dx.doi.org/10.1002/hec.3462

\section{PUBLISHER}

(c) Wiley

\section{VERSION}

AM (Accepted Manuscript)

\section{PUBLISHER STATEMENT}

This work is made available according to the conditions of the Creative Commons Attribution-NonCommercialNoDerivatives 4.0 International (CC BY-NC-ND 4.0) licence. Full details of this licence are available at: https://creativecommons.org/licenses/by-nc-nd/4.0/

\section{LICENCE}

CC BY-NC-ND 4.0

\section{REPOSITORY RECORD}

Castro, Vitor. 2019. "Pure, White and Deadly... Expensive: A Bitter Sweetness in Health Care Expenditure". figshare. https://hdl.handle.net/2134/23769. 
Pure, white and deadly... expensive:

\title{
A bitter sweetness in health care expenditure
}

\author{
Vitor Castro ${ }^{\mathrm{a}, \mathrm{b}, *}$ \\ ${ }^{a}$ Faculty of Economics, University of Coimbra, Portugal \\ ${ }^{\mathrm{b}}$ NIPE, University of Minho, Portugal
}

\begin{abstract}
This paper analyses the impact of sugar availability/intake on diabetes expenditure and on total health care expenditure. Building this macroeconomic analysis upon the literature on the determinants of health care expenditure, we estimate a dynamic panel data model over a sample of 156 countries for the period 1995-2014. After controlling for the traditional determinants of health care spending, we find that an increase in sugar availability/intake leads to a significant rise in diabetes expenditure (per capita and per diabetic) and in the growth rate of total health care expenditure per capita. Moreover, we show that this causal relation is present in both developed and developing countries.
\end{abstract}

JEL: C23, I10.

Keywords: Diabetes expenditure; Health care expenditure; Sugar availability; GMM estimator.

\footnotetext{
* Faculty of Economics, University of Coimbra, Av. Dias da Silva 165, 3004-512 Coimbra, Portugal. Economic Policies Research Unit (NIPE), University of Minho, Campus of Gualtar, 4710-057 Braga, Portugal. Phone: +351 239 790543; Fax: +351 239 790514; E-mail: vcastro@ fe.uc.pt
} 


\section{Introduction}

In the 1960s, John Yudkin, a British physiologist and nutritionist, called the attention to the negative impact of sugar consumption on health. According to his studies, the rise in the consumption of sugar was leading to an increase in the incidence of diseases, like coronary thrombosis, dental caries, obesity, diabetes, liver disease, dyspepsia and some cancers. His book "Pure, White and Deadly" summarizes very eloquently the damages caused by sugar on health and the respective costs for society (Yudkin, 1988). His message was not very welcome by the sugar industry and by the manufacturers of processed foods, who have been accused of using large quantities of sugar in their products. They discredited Yudkin's work and impeded it from being widespread. Only in the beginning of this decade, Robert Lustig, a pediatric endocrinologist of the University of California, brought the sugar again to the centre of the discussion.

Robert Lustig's research shows that sugar overconsumption has serious negative effects on health, in particular, and on the society, in general. The long-term economic, health care and human costs are considerable. For example, “The United States spends $\$ 65$ billion in lost productivity and $\$ 150$ billion on health-care resources annually for morbidities associated with metabolic syndrome. Seventy-five per cent of all US health care dollars are now spent on treating these diseases and their resultant disabilities." (Lustig et al., 2012, p. 28). More recently, the Morgan Stanley Research issued a report that states that "where estimates of total costs exist, these range between $1 \%-2 \%$ of a country's GDP.” (Morgan Stanley, 2015, p. 16). The report also emphasizes the indirect costs of sugar overconsumption to economy: increased mortality, reduced workforce, loss of productivity and, ultimately, a decline in economic growth.

In an empirical analysis for a panel of 175 countries over the period 2000-2010, Basu et al. (2013) unveil the presence of a strong relationship between the incidence of diabetes and sugar availability. The authors investigated whether the availability of other food groups including, oils, meats, cereals, fruits and fibers - as well as socioeconomic factors such as income, urbanization and aging - were related to diabetes prevalence, but they only found statistically significant evidence of a sugar-diabetes link.

In our study, we move a step forward and analyse whether the increase in sugar availability/intake is causing health care expenditure to rise. We start by looking at the impact of sugar intake on diabetes expenditure - given the proven significant relation between sugar and the prevalence of this disease (Basu et al., 2013) - and then we evaluate its impact on total health care 
expenditure. One important argument in favour of the study of this relation is the alarming fact that $75 \%$ of the health care expenditure in the US is concerned to diseases or health conditions related to sugar overconsumption (Lustig et al, 2012). The Credit Swiss Research Institute highlights that "The future costs of dealing with all these diseases are putting further pressure on the private and public sectors' finances alike." (Credit Swiss, 2013, p. 4). Moreover, the International Diabetes Federation (IDF) estimates that by the end of 2015 "diabetes will have caused 5.0 million deaths and have cost between USD 673 billion and USD 1197 billion in healthcare spending. If this rise is not halted, by 2040 there will be 642 million people living with the disease.” (IDF, 2015, p. 9). This report also mentions some figures for 2040 spending with diabetes, which "is projected to exceed USD 802 billion to USD 1452 billion in today's dollars.” (IDF, 2015, p. 58). In a descriptive study for five European Union countries, Kanavos et al. (2012) calls the attention to the indirect costs of diabetes (reduced productivity, absenteeism, early retirement, social benefits and career costs) and its complications, which are likely to be underestimated. They state that the indirect costs "can exceed direct costs by at least a factor of 2 - or even 3 - to 1 , depending on the country." (Kanavos et al. 2012, p. 1). Hence, many arguments are put forward to the need of a cause-effect study on the health care costs of sugar consumption.

To proceed with this study, we build our analysis upon the standard literature on the determinants of health care expenditure and estimate a dynamic panel data model over a sample of 156 countries for the period 1995-2014. Accounting for the traditional determinants of health care expenditure - income, population structure, medical/technological progress, urbanization, female participation in the labor force, share of public health expenditure, hospital beds, air pollution, among others - we find that an increase in sugar availability leads to a significant rise in diabetes expenditure (per capita and per diabetic) and in the growth rate of total health care expenditure per capita. This trend is observed in both developed and developing countries.

The paper is organized as follows. Section 2 presents a review of the literature. Section 3 describes the data and presents the econometric model. The main results are presented and discussed in section 4. Section 5 concludes.

\section{Review of the literature}

The seminal work of Newhouse (1977) has set the agenda to the analysis of the determinants of health care expenditure. His study identified income as the main cause of 
healthcare expenditure in 13 OECD countries. Other subsequent studies, also with cross-sectional data for OECD countries, confirmed this result (Leu 1986; Parkin et al., 1987; Gerdtham et al., 1992; among others). An important issue considered in this (so-called) first generation of studies on the determinants of health care expenditure was the question of whether health care is a luxury or a normal good, i.e. whether a larger than proportionate increase in income (GDP per capita) is spent on health care or not. Most of the first generation studies find income elasticity higher than one, concluding that health is a luxury good.

Despite some studies start to consider other variables, like the share of population below 15 and above 64 years, share of urban population, share of public health expenditure, ratio of female participation in the labor force, they relied only on cross-section data, which means that they could not control for individual country differences. Moreover, the econometric models employed in those studies were very basic and the absence of some variables may have led to a specification bias of omitted variables generating large income elasticities.

However, in the 1990s emerges a second-generation of studies that rely on the use of time series and panel data. They start to find income elasticities close to one, implying that health is a normal good (Culyer, 1990; Hitiris and Posnett, 1992). Panel data also allows an increase in the size of the sample and the control for specific country and time effects. At the same time, a wide range of variables that vary over time are considered and more papers analyse the impact of population ageing, urbanization, share of public financing to total health expenditure, and female participation in the labor force on health care spending. Despite most of these variables are found to be relevant (see, for example, Gerdtham et al. (1992); Hitiris and Posnett (1992); and Barros, 1998), no consensus was reached regarding the importance of population aging. ${ }^{1}$

The stationarity of the series became an important issue. Hansen and King (1996) consider inadequate the studies by Culyer (1990) and Hitiris and Posnett (1992), because the time series they use are not stationary. Thus, the use of time-series data call the attention to the issue of nonstationarity - which implies that conventional hypothesis testing procedures based on the critical values of the tests are not valid. These concerns led some authors to develop approaches that take into account the non-stationarity of the series and to implement panel unit root and cointegration

\footnotetext{
${ }^{1}$ While Blomqvist and Carter (1997) show that population ageing is associated with per capita higher health care expenditure, Getzen (1992) and Barros (1998) do not find evidence to support that hypothesis for a panel of OECD countries. Zweifel et al. (1999) reach the same result but using longitudinal individual data collected from a Swiss health insurer instead of macroeconomic data as the other studies.
} 
tests. This constitutes the so-called third generation of studies on the determinants of health care expenditure. They end up finding that health care income elasticities are less than unity and, in some cases, no long-run relationship between health care expenditure and income is found (see Hansen and King, 1996; and Blomqvist and Carter, 1997). Nevertheless, the controversy on whether the series used are non-stationary or not, in the first place, remains. ${ }^{2}$

The discussion proceeds over this millennium, with several studies confirming that per capita income remains as the main determinant of per capita health care expenditure and that it is more a necessity rather than a luxury (Giannoni and Hitiris, 2002; Baltagi and Moscone, 2010; Colombier, 2012; and Hosoya, 2014). Population aging has also assumed some relevance (Herwartz and Theilen, 2010; Christiansen et al., 2006; and Hosoya, 2014).

Despite the relevance of the urbanization, the role of both the share of public financing to total health expenditure and the female participation in the labor force has been reinforced in some recent studies. Other variables have also been added to the analysis, like medical and technological progress, usually controlled with the inclusion of a time-trend variable, ${ }^{3}$ and supply side variables. For example, in studies for European countries, OECD countries, and US states, respectively, Christiansen et al. (2006), Mosca (2007) and Wang (2009) call the attention to the importance of the number of physicians, hospital beds, diagnostic and treatment technologies, and the centralization/decentralization of health care system. ${ }^{4}$

This paper extends the literature on the determinants of health care expenditure in several directions. First, the studies on this topic are essentially implemented over panels of OECD countries or individual (developed) countries, and very little attention has been given to the world-

\footnotetext{
${ }^{2}$ While McCoskey and Selden (1998) reject the null hypothesis of unit roots for health care expenditure and GDP, Roberts (1999) finds both variables to be non-stationary. Gerdtham and Lothgren (2000), using panel cointegration tests over 21 OECD countries, show that both have a unit root but they are cointegrated. For a deep survey on the initial generations of studies in this field, see Gerdtham and Jonsson (2000).

${ }^{3}$ See, for example, Herwartz and Theilen (2003), Herwartz and Theilen (2010), Colombier (2012). Moreover, taking into account nonlinearities in the relation between health care and its determinants, Wu et al. (2014) show that ignoring technological change and age structure results in an overestimation of income elasticity.

${ }^{4}$ For a survey on the recent literature, see Martin at al. (2011). Another strand of the literature has recently turned the attention to the Baumol's cost disease (Hartwig, 2008; Colombier, 2012; Bates and Santerre, 2013; Medeiros and Schwierz, 2013; and Hartwig and Sturm, 2014), trying to explain health care expenditure as driven by wage increases in excess of productivity growth. However, the lack or poor quality of the data, especially for wages, makes it impossible to test it for developing countries. Moreover, the Baumol effect is a phenomenon that affects mainly developed economies. Thus, that analysis is not under the scope of our study.
} 
wide analysis. In this paper, we take a step forward in that direction by considering 156 countries in our dataset and separate assessments for OECD and Non-OECD countries as a way of distinguishing the effects between developed and developing countries. As far as we are concerned, only Xu et al. (2011), using a panel of 143 countries over the period 1995-2008, tries to understand the trajectory of health expenditure in developing countries by decomposing the analysis in government health expenditure and out-of-pocket payments. In this paper, despite we consider more countries and years of observations, we follow a different approach, emphasizing the role of sugar intake and comparing the results between developed and developing countries.

Second, although many recent studies are concerned with stationarity issues, they do not take into account the possible dynamics of health care expenditures by controlling for its $\operatorname{lag}(\mathrm{s}) .^{5}$ Not controlling for the persistence of the dependent variable, when it is present, generates biased estimates (Bond, 2002; Baltagi, 2013). Hence, in this study, we are not only concerned with stationarity issues, but also with the persistence in the dependent variable. We employ a dynamic panel data analysis where those problems are tackled with a system-GMM estimator. At the same time, endogeneity concerns regarding some regressors are taken into account. An additional advantage of the dynamic panel models is their ability to identify both short-run impact and longrun institutional effects (Baltagi, 2013).

Third, the literature is essentially focused on the total health care expenditure, without considering any of its components. Given the aim of this study, we also look at one of its components: diabetes expenditures. Besides the importance of income and population aging, Basu et al. (2013) emphasize the significant impact that sugar has in increasing the prevalence of diabetes. Here, we move a step forward by testing for its impact on diabetes expenditure. This analysis is of ultimate relevance as IDF (2015) estimates a significant increase in direct and indirect costs related to diabetes. Those costs include an increased use of health services, loss of productivity, disabilities and premature mortality. Consequently, this "imposes a large economic

\footnotetext{
${ }^{5}$ Only recently An et al. (2016) provide a dynamic analysis for the impact of public pensions on aggregate health spending for a panel of OECD countries. Magazzino and Mele (2012) and Bilgel and Tran (2013) also take into account the persistence of the dependent variable in their panel data analysis of the determinants of health care expenditures for Italian and Canadian regions, respectively. Despite both use variables in levels, the first does not take into account the stationarity issue, which raises doubts on the validity of their estimates. The dynamic panel data analysis provided by Xu et al. (2011) suffers from the same problem.
} 
burden on individuals and families, national health systems and countries; it therefore represents a significant obstacle to sustainable economic development.” (IDF, 2015, p. 58). ${ }^{6}$

Finally, despite during recent years studies on the determinants of health care expenditure have increased both in methodological complexity and in the identification of causal variables, they have given little attention to the role of lifestyle and behaviour. The exceptions are Gerdtham et al. (1998), with a particular emphasis on the contractual relations between payers, providers and patients, and Hartwig and Sturm (2014). ${ }^{7}$ However, as far as we are concerned, no study has considered the impact of sugar intake on total health care expenditure.

According to a report issued by the Morgan Stanley in March 2015, sugar consumption per capita "has increased almost fivefold over the past century. At the beginning of the 20th century, a world population of 1.6 billion people consumed roughly 8 million tonnes of sugar, i.e. $5.1 \mathrm{~kg}$ per capita. Today, a world population of 7 billion consumes 166 million tonnes of sugar (including high-intensity sweeteners), that is $24 \mathrm{~kg}$ per person, equivalent to around 230 kilocalories per day or $8 \%$ of the total daily energy intake." (Morgan Stanley, 2015, p. 12). The data provided by Food and Agriculture Organization (FAO) on sugar and sweeteners food supply (a proxy for sugar consumption) for the period 1961-2011 allow us to conclude that the world food supply of sugar and sweeteners has almost tripled over that period (see Figure 1).

\section{[Insert Figure 1 around here]}

Excessive sugar intake is considered by the medical community to have a direct negative impact on health and contributed to the development of several diseases: diabetes, metabolic syndrome, obesity, heart and liver diseases, dental caries, and cancers. ${ }^{8}$ The alarming observation

\footnotetext{
${ }^{6}$ See also Credit Swiss (2013), Kanavos et al. (2012), and Morgan Stanley (2015).

${ }^{7}$ Christiansen et al. (2006) make an attempt to control for tobacco and alcohol consumption using OECD data, but their results are not consistent between the samples they use (11 and 15 EU countries). Nevertheless, the aim of their study is to analyse the relationship between ageing and the development in the aggregate health care expenditure. Panopoulou and Pantelidis (2012) are the first to consider food variables like sugar, fruits and vegetables consumption, but their analysis is only focused on finding convergence in per capita health care expenditures and in its various potential determinants and not on testing a proper cause-effect relationship between health care spending and its determinants.

${ }^{8}$ See, among others, Yudkin (1988), Lustig and Nguyen (2010), Lustig et al. (2012), Basu et al. (2013), Lustig (2013), Null (2014), and Jiang et al. (2016). Moreover, Or (2000) shows that sugar consumption is positively related to male and female mortality in a sample of 21 OECD countries over the period 1970-1992.
} 
that a substantial share of health care expenditure has been devoted to the treatment of those diseases in developed economies - considered to be to be related to sugar overconsumption by medical experts (Lustig et al, 2012; Lustig, 2013) - brings the issue of health care costs of sugar to the agenda. Hence, the study of the impact of sugar on diabetes and health care spending becomes of primordial importance for the understanding of their relationship and to provide valuable insights on how public authorities might tackle the problems that arise from excessive sugar consumption.

In sum, taking into account, as a starting point, the literature on the determinants of health care expenditure and on the health effects of excessive sugar intake, the two main hypotheses that we intend to test in this macroeconomic analysis are the following:

H.1: A rise in sugar intake has a significant positive impact on diabetes expenditures.

H.2: A rise in sugar intake has a significant positive impact on total health care expenditures.

\section{Data and econometric specification}

To explore the impact of sugar on diabetes expenditure and total health care expenditure, we use a (panel) database with a cross-sectional component of up to 156 countries and a workable temporal component covering the period from 1995 to 2014, for a wide range of variables.

\subsection{Data}

The data used in this study comes from several sources. For the dependent variables on the diabetes expenditure, the data were collected from various issues of the International Diabetes Federation (IDF) Diabetes Atlas for the period 2003-2014. These Atlas provide world countries estimates on diabetes prevalence, health expenditure for diabetes and mean diabetes related expenditure per person with diabetes (in USD). We use the last two to obtain our diabetes expenditure (dependent) variables: the real health expenditure for diabetes per capita $\left(r d i a b \_\exp \_p c\right)$; and the mean diabetes related expenditure per person with diabetes $\left(r d i a b \_e x p \_p p d\right)$. The per capita values in the first variable were computed dividing the health expenditure for diabetes by the total population; the consumer price index (base-year, 2010) was used to calculate the real values of both variables. The consumer price index and population were obtained from the World Development Indicators Database. The data for the dependent variable on total health expenditure comes from the World Development Indicators (WDI) Database of the 
World Bank. The time period is longer than for diabetes expenditures, as the available data ranges from 1995 to 2014. The consumer price index (base-year, 2010) was also used to obtain the respective real total health care expenditure per capita $($ rhcepc). From this, we computed the respective growth rate $\left(r h c e p c \_g r\right)$.

To estimate the relation between sugar and health expenditures, we use several measures for sugar: sugar and natural sweeteners, in kilocalories per person per day (sugar_swt_kcal); refined sugar, in kilocalories per person per day (sugar_ref_kcal); sugar and natural sweeteners, in grams per person per day (sugar_swt_gcd); and the percentage of sugar and natural sweeteners kilocalories in total kilocalories of food per person per day (sugar_ptot_kcal). These data comes from the Food and Agricultural Organization food supply data (FAOSTAT) of the United Nations. Our expectation is that higher sugar availability will be associated to increasing health care spending with diabetes and in total.

The control variables are related to the literature on the determinants of health care expenditures and consider measures like real GDP per capita (rgdppc) and its growth rate (rgdppc_gr), percentage of population under 15 years old (pop014), percentage of population above 64 years old (pop65abv), percentage of urban population (urban_pop_ptot), female labor force participation rate (lfp_female), public health care expenditure as percentage of total health care expenditure (hce_pub_texp), number of hospital beds per 1000 inhabitants (hosp_beds) and its growth rate (hosp_beds_gr), and percentage of population exposed to air pollution (pollut_pop). The data for these variables were collected from the WDI Database. According to the literature, we expect that most of these variables are relevant to explain health care spending.

Other additional controllers are also considered, like the national diabetes prevalence (diab_nprev), percentage of obese adults (obese_prev), market availability of different food items (total food, fat, protein, animal products, oils, cereals, fruits, vegetables, meat, fish and alcohol) and other proxies for the traditional determinants of health care expenditure. The full list and description of variables used in this study, the respective sources and means are reported in Table 1.9

\section{[Insert Table 1 around here]}

\footnotetext{
${ }^{9}$ The complete descriptive statistics are provided in Table A1 in Annex. At the bottom of that table is also presented the list of countries considered in our sample.
} 
With these data we can start to evaluate the validity of the two hypotheses formulated in this study (H.1 and H.2). As an initial and simple exercise, we report a set of graphs in Figure 2 showing the relation between sugar availability and diabetes prevalence, diabetes expenditure and total health care expenditure, respectively, for the year of $2010 .{ }^{10}$ The graphs show a positive relationship between sugar and sweeteners food supply/availability (in kilocalories, per person per day) and all the other variables. Basu et al. (2013) have already confirmed empirically the positive impact of sugar availability on diabetes prevalence, so we will focus on the other three cases. It is clear from the picture that countries with higher sugar intake present higher levels of diabetes expenditure per capita and per diabetic, and higher total health care expenditure per capita.

\section{[Insert Figure 2 around here]}

However, this graphical analysis does not take into account the effects of other important economic and socio-demographic characteristics on health care expenditures, like the level of income per capita and the structure of the population. After controlling for those well-established conditionings in the literature (and all time periods available), is sugar intake still playing a role in explaining higher diabetes and health care expenditures? The aim of the next section is to provide the adequate econometric tools to help us to answer this question.

\subsection{Econometric model}

To estimate the impact of sugar on diabetes expenditure and on total health care expenditure for all time periods and countries in our dataset, we consider the following two dynamic panel data specifications:

$$
\begin{aligned}
\text { lnrdiab_exp_pc } c_{i t}= & \alpha+\rho \ln r d i a b \_e x p \_p c_{i t-1}+\beta \ln s u g a r \_s w t \_k c a l_{i t}+\gamma_{1} r g d p p c \_g r_{i t}+ \\
& \gamma_{2} p o p 014_{i t}+\gamma_{3} p o p 65 a b v_{i t}+\delta t_{r e n d}+v_{i}+e_{i t},
\end{aligned}
$$

where $i=1, \ldots, 156$ and $t=2003, \ldots, 2014$; and

$$
\begin{aligned}
r h c e p c \_g r_{i t}= & \alpha+\rho r h c e p c \_g r_{i t-1}+\beta s u g a r \_s w t \_k c a l_{i t}+\gamma_{1} r g d p p c \_g r_{i t}+\gamma_{2} p o p 014_{i t}+ \\
& \gamma_{3}{ }_{3} \text { op } 65 a b v_{i t}+\boldsymbol{\theta} \mathbf{X}_{i t}+\delta t r e n d_{t}+v_{i}+e_{i t}
\end{aligned}
$$

where $i=1, \ldots, 156$ and $t=1995, \ldots, 2014$.

\footnotetext{
${ }^{10}$ Similar pictures are obtained for other years, but we choose 2010 because it is the more recent year for which we have observations for the higher number of countries in our sample.
} 
The coefficient on the lag of the dependent variable $(\rho)$ measures its persistence. The vector $\beta$ captures the impact of sugar availability, while the vectors $\gamma_{j}(j=1,2,3)$ assess the effect of the economic conditionings and demographic structure of the population on diabetes and health care expenditures. $\mathbf{X}_{i t}$ is the vector of the additional control variables (those variables are described in Table 1). As in the literature, the time trend is used here as a proxy for medical or technological progress. Regarding the last components, $v_{i}$ is the individual effect of each country $i$, and $e_{i t}$ is the error term.

Given the presence of individual effects, $v_{i}$, the model can be estimated assuming those effects as fixed or random. However, the lagged value of the dependent variable would be correlated with the error term even if the latter is not serially correlated. This implies that OLS estimates (random or fixed effects) will be biased and inconsistent (Baltagi, 2013). The estimators that take into account that bias can be grouped into: (i) bias-corrected estimators; and (ii) instrumental variables estimators.

Bias-corrected estimators, like the one proposed by Bruno $(2005 \mathrm{a}, \mathrm{b})$ - the bias-corrected least squares dummy variable estimator (LSDVC) for dynamic panel data models - are suitable when the number of individuals $(\mathrm{N})$ is small (and $\mathrm{T}$ is not very large). Although $\mathrm{T}$ is not large in this study, the number of individuals cannot be considered small $(\mathrm{N}=156)$. Hence, this estimator is not a suitable tool to solve the bias problem caused by the inclusion of the lag of the dependent variable in the list of regressors.

According to the large sample properties of the generalized method of moments (GMM), the dynamic estimator proposed by Arellano and Bond (1991) is adequate when there is a clear dominance of cross sections $(\mathrm{N})$ over time periods $(\mathrm{T})$ in the sample. This is what happens in our panel, which means that this estimator is a more appropriate procedure to solve the bias problem. Moreover, it allows estimating the dynamic model in a more consistent and efficient way.

Taking first differences of equations (1) and (2), levels of the explanatory variables can be used as instruments to avoid correlation between the respective lagged dependent variable and the country-specific effects. Arellano and Bond (1991) also proposed a variant of the GMM estimator, namely the two-step estimator, which utilizes the estimated residuals in order to construct a consistent variance-covariance matrix of the moment conditions. The two-step estimator is asymptotically more efficient than the one-step estimator and relaxes the assumption of homoscedasticity, which generates efficiency gains. 
Arellano and Bover (1995) and Blundel and Bond (1998) suggested additional moment conditions, since, as long as valid, they increase the efficiency of the estimators. This GMM estimator that combines the moment conditions of the model in first differences and those of the model in levels (differences are used as instruments for the level equations) is known as the system-GMM estimator. This allows estimating the model with higher accuracy, reducing the finite sample bias (Bond, 2002; Baltagi, 2013). ${ }^{11}$

An additional problem that we have to deal with is the "too many instruments problem". Too many instruments may result in over-fitting biases. When the number of time periods is relatively large, this over-fitting becomes serious. The consequent large collection of instruments, even if individually valid, can be collectively invalid because they over-fit endogenous variables (Doornik et al., 2002; Roodman, 2009a, b). They also weaken the Hansen test of overidentifying restrictions used to check instrument validity. To minimize the over-fitting problem we use the collapse alternative suggested by Roodman (2009b). This procedure allow us to create one instrument for each variable and lag distance, rather than one instrument for each time period, variable and lag distance as it divides the moment conditions in the GMM equations into groups. Then, the conditions in each group are added to form a smaller set of conditions.

\section{Empirical results}

In this section are presented and discussed the empirical results. First, we analyse the evidence from the diabetes expenditure. Then, we proceed with a more extensive, deeper and enlightening analysis of the impact of sugar intake on total health care expenditure.

\subsection{Diabetes expenditure}

The results of system-GMM estimations for the diabetes specifications are reported in Table 2. We start by showing the results for the case in which the log of real health expenditure for diabetes per capita (Inrdiab_exp_pc) is the dependent variable; in a second set of results the

\footnotetext{
${ }^{11}$ For this to be valid, the system-GMM requires the stationarity of the variables and the lack of correlation between the first-differences of the instruments and the specific effects (Baltagi, 2013). Im-Pesaran-Shin and ADF Fisher-type panel unit root tests were performed for the dependent and independent variables used in this study. The results are presented in Annex (see Table A.2) and show that the null hypothesis that all panels contain unit roots is rejected for all the variables that we use in our regressions. This also justifies why the dependent variable is in levels in the diabetes specification and in growth rates in the case of total health care.
} 
dependent variable is replaced by the log of mean diabetes related expenditure per person with diabetes (lnrdiab_exp_ppd). ${ }^{12}$ The use of these two measures allows us to account for the relative importance of spending on diabetes in the total population and in the population affected by the disease. The first measure makes also the results more comparable with the ones for total health care expenditure per capita.

A concern in this kind of empirical analysis is the possibility that the explanatory variables are endogenous. The system-GMM estimator employed here controls for the potential endogeneity of some covariates (lag of the dependent variable, growth of real GDP per capita and sugar and sweeteners availability) by using their lagged instruments in the first-difference and level equations. The other variables are considered exogenous (pop014, pop65abv, and trend) and instrumented with their contemporaneous values. ${ }^{13}$

Two-step results using robust standard errors corrected for finite samples are reported in parenthesis and the respective significance level is indicated with stars. The number of observations, countries, and instruments, as well as the $p$-values for the Hansen, Difference-inHansen, and autocorrelation tests are reported at the bottom of the Table 2.

\section{[Insert Table 2 around here]}

The system-GMM estimator accounts for the dynamic bias that results from the inclusion of the lagged dependent variable in the specifications. However, the problem may not completely disappear, as this estimation method assumes weak exogeneity of the explanatory variables. This means that they can be affected by the past and current values of diabetes expenditure but must be uncorrelated with future realizations of the error term, i.e. future unanticipated shocks to diabetes expenditure should not affect the current value of the explanatory variables. The statistical validity of this assumption is supported by the results of the Hansen-test, which, in general, does not reject the validity of the overidentifying restrictions (except in regression 6). The results for the difference-in-Hansen test are also considered to assess the validity of the GMM instruments of the

\footnotetext{
${ }^{12}$ Both variables are stationary as required. See panel unit root tests in Table A.2 in Annex. In some experiments not reported here but available upon request - suggested by one of the referees, we also considered these variables and sugar intake in growth rates, but the conclusions did not change.

${ }^{13}$ More specifically, the respective lagged values and the other explanatory variables are used as instruments in the first-differences equation and their first-differences are used in the levels equation. They are collapsed to avoid the problem of having too many instruments.
} 
levels equation: their validity is not rejected either (with the exception of regression 6). Finally, the tests for autocorrelation of the differenced residuals - AR(1) and $\mathrm{AR}(2)$ - reject second-order autocorrelation, further supporting the validity of the instruments used. Hence, one lag of the dependent variable has proved to be sufficient to account for its persistence.

The empirical results reported in Table 2 are very robust in showing that sugar and natural sweeteners availability has a significant positive impact on diabetes expenditure per capita and per diabetic. In particular, and since we have a log-log specification, a 1\% increase in sugar availability is estimated to generate an immediate increase in real diabetes expenditure per capita of around $2.5 \%$. In the long-run the impact will be even higher: $4.70 \%(=2.5 /(1-0.47))$. This means that for each additional teaspoon of added sugar, diabetes expenditure will rise, on average, by roughly $26.8 \%$ in the long-run. ${ }^{14}$ When we look only at the population of diabetics, the estimated magnitude of the impact is lower $(0.8 \%-0.9 \%)$ in the short-run, but in the long-run it is closer: $4.06 \%(=0.8 / 1-$ 0.79). Nevertheless, what does this mean in terms of the actual value of this impact in dollars? The mathematical correspondence between the two coefficients can be better understood if we look at the impact in terms of the original unit of measure (dollars) than in terms of percentages.

As we have a log-log relation between the dependent (diabetes) variables and sugar intake, the analysis is made in terms of percentages. The fact of the magnitude of the impact in percentage is higher in per capita than in per diabetic terms does not mean that the impact in dollars is higher in the first than in the second case. In the first analysis, as we are dividing diabetes spending by more people (population), the values in dollars will be lower than when we divide it by only the diabetic people. Hence, the magnitudes of diabetes spending per capita and per diabetic in dollars will be different and may lead to opposite results when we analyse the results on that basis. For

\footnotetext{
${ }^{14}$ Considering that a teaspoon corresponds to 4 grams or 16 kilocalories of sugar and that this amount represents $5.7 \%$ of the mean of sugar_swt_kcal (i.e. 100*16/279.2; see Table A.1 in Annex), we just need to multiply 5.7 by 4.7 to reach the value of $26.8 \%$. This is a large effect. However, the level of sugar availability/intake also reached a huge level in the time period considered in this analysis (2003-2014; see, for example, Figure 1). Hence, a small increase in sugar intake during this period can have a large effect on people's health conditions, promoting the development of diabetes in more and more people and, consequently, increasing quite rapidly the level of spending with diabetes. Considering the high levels of sugar consumption observed over that period (see also: Credit Suisse, 2013; IDF, 2015; and Morgan Stanley, 2015) it is not unlikely that one more teaspoon of sugar intake, on the top of an already high level of consumption, might have a huge and higher effect on diabetes spending than it might have had in the past, when the average consumption was lower and, for that reason, one additional teaspoon of sugar would not increase so much the costs to treat a few more diabetics.
} 
example, considering the means of diabetes expenditure per capita (85.05) and per diabetic (909.00) - see Table A.1 in Annex - if we multiply them by the respective estimated long-run coefficients (4.70\% and $4.06 \%$, respectively), we get the following marginal effects on the average, respectively: 4.0 dollars $(=4.70 \% * 85.05)$ and 36.9 dollars $(=4.06 \% * 909.00)$. Thus, when sugar intake increases by $1 \%$, we estimate that diabetes expenditure per capita will increase, in the longrun, approximately 4.0 dollars, while in per diabetic terms the increase will be approximately 36.9 dollars. A similar pattern in the magnitudes can be found if we look, instead, at the short-term impact in dollars on the average.

Similar findings are obtained when we split the sample in OECD and Non-OECD countries. One important result that stands from that analysis is the fact that the impact of sugar on diabetes expenditure is higher (in magnitude) in the first group. Developed countries might have more resources to deal with the 'problem', but probably the 'problem' has already reached higher proportions there (Lustig et al, 2012; Lustig, 2013; Credit Suisse, 2013; Morgan Stanley, 2015).

In sum, these results are in line with our expectation, confirming our first hypothesis that a higher sugar intake increases diabetes expenditure. This is the case after controlling for income per capita, population, trend for medical/technological progress and even for diabetes prevalence. Real GDP per capita has a significant (positive) coefficient only in the specifications where lnrdiab_exp_pc is the dependent variable and when its stationary growth rate is used (see columns 2 and 3 in Table 2). Regarding the effects of the structure of population, population aging, in particular, presents a significant impact on diabetes expenditure: it increases when the share of elderly people is higher. Nevertheless, the effect is not very relevant in Non-OECD countries. As expected, technological changes are positively associated with diabetes expenditure. Finally, diabetes prevalence boosts diabetes expenditure per capita, especially in Non-OECD countries, but not the average spending per diabetic. As more diabetics will require more resources, in per capita terms we observe an increase in spending, but in per diabetic terms the expenditure will not change much (as more resources are divided by more patients).

The prevalence of obesity was also considered in some additional experiments reported in Table A.3 in Annex, but no significant effects were found for the coefficient on that variable (obese_prev). One reason for that lack of significance might be the fact that a person does not need to be obese to be diabetic. There are many people not suffering from obesity but that are diabetic and obese people that are not diabetic. The issue that obesity causes diabetes is not clearly 
established in the literature. For example, Lustig (2013, Ch.8), says that in the US “Twenty percent of morbidly obese adults have completely normal metabolic status, no evidence of disease, and normal longevity. [Moreover] ...50 percent of women and 20 percent of men who are categorized as normal on the basis of their BMI are actually obese based on their carriage of visceral (bad) fat. [...] Bottom line, it's your visceral fat, in particular your liver fat, that counts."

Thus, the "BMI obesity" might not be the best way to test whether obesity is increasing diabetes spending; we should look instead at the "visceral obesity", because that can cause more damage. However, those data are not available for a macro-analysis like this. Nevertheless, we decided to explore this issue in greater detail and considered instead a variable for obesity that corresponds to the residuals of the regression of obesity prevalence on sugar intake (resid_obese). That new variable represents the part of obesity prevalence that is not explained by sugar intake. We did the same for diabetes prevalence and created the variable resid_diab (See Table A.3 in Annex). ${ }^{15}$ The results confirm the relevance of diabetes prevalence (the part not explained by sugar intake) on diabetes expenditure per capita but not on per diabetic. The part of obesity prevalence not explained by sugar intake remains insignificant. Thus, by the reasons indicated above, obesity prevalence by itself might not indeed be driving diabetes spending. Sugar intake is playing a more important role on that matter, either for thin or fat people.

\subsection{Total health care expenditure}

The practical limitations inherent to the diabetes expenditure variables - like the short time period of data available, the method used by the IDF to obtain the respective estimates (see IDF Diabetes Atlas for further details), and the fact of some missing observations had to be generated by linear interpolation - are detrimental to proceed with the analysis of the impact of sugar intake on total health care expenditure. In this case, the time period is longer and the quality of the data is much less questionable. Furthermore, another of the aims of this study is precisely to check the hypothesis of whether sugar and natural sweeteners availability is driving an increase in total health care spending (hypothesis H.2).

The first set of results of the system-GMM estimations for the total health care specifications is reported in Table 3. In this initial analysis, we consider several measures for sugar and (only) the basic controllers referenced in the literature (and used in the diabetes regressions

\footnotetext{
${ }^{15} \mathrm{We}$ are grateful to one anonymous referee for bringing this issue to our attention.
} 
above); income, population and 'technological' trend. Due to the required stationarity properties, the dependent variable is not in levels but in growth rates: the growth rate of real health care expenditure per capita (rhcepc_gr) - see Table A.2 in Annex.

The two-step system-GMM estimator controls for the potential endogeneity of the lag of the dependent variable, growth of real GDP per capita and sugar and sweeteners availability by using their lagged instruments in the first-difference and level equations. All the other variables are considered exogenous and instrumented with their contemporaneous values. ${ }^{16}$ In this case, the Hansen-test never rejects the validity of the overidentifying restrictions, and the results for the difference-in-Hansen test also support the validity of the GMM instruments of the levels equation. Moreover, the autocorrelation tests reject second-order autocorrelation, as required, further supporting the validity of the instruments used.

\section{[Insert Table 3 around here]}

We start by ignoring the stationarity issues and estimate a model in logs (see column 1 in Table 3) to compare the results with the literature that looks at the elasticity of income. In this case two lags of the dependent variable are needed to eliminate the second-order autocorrelation. The results show that an increase of $1 \%$ in the kilocalories of sugar and natural sweeteners lead to an immediate rise of $0.26 \%$ in real total health care expenditure per capita; in the long run it will represent an increase of $0.93 \% .{ }^{17}$ Thus, we have here clear evidence of a significant effect of sugar intake on health care expenditure.

The results for the controllers are in line with the literature, showing that real health care expenditure per capita increases with real GDP per capita, population aging and medical or technological progress. In particular, they show that the (long-run) income elasticity is well below one $(0.46 \%)$, confirming that health care is a necessity (rather than a luxury) for this sample of more than 150 countries.

Stationarity is a concern in these models, so we proceed by only considering stationary series. Columns (2)-(7) in Table 4 report results for several measures of sugar: logarithm of sugar

\footnotetext{
${ }^{16}$ Similarly to what we have done in the diabetes estimations, lagged values of the endogenous variables and the other explanatory variables are used as instruments in the first-difference equation and their first-differences are used in the levels equation. They are collapsed to avoid the problem of having too many instruments.

${ }^{17}$ Taking into account the dynamics of the adjustment in the model: $0.93=0.26 /[1-(0.94-0.22)]$.
} 
and sweeteners in kilocalories (per person, per day), growth rate, ${ }^{18}$ sugar and sweeteners in kilocalories (per person, per day), percentage of total food, refined sugar (per person, per day), and sugar and sweeteners in grams (per person, per day). The results are very robust in showing a significant positive impact of sugar on the growth rate of total real health care expenditure per capita, corroborating our hypothesis H.2 that a higher sugar intake increases total health care expenditure. Moreover, they support the observed growth in health expenditure devoted to diseases or health conditions related to sugar overconsumption (Lustig et al, 2012; Lustig, 2013; Credit Suisse, 2013; Morgan Stanley, 2015).

The growth rate of real GDP per capita and the 'technological' trend also present the expected positive and significant impact. The results for the structure of the population are not very robust but they support the idea that health care expenditure tend to be higher when the percentage of young (and, in some cases, elderly) people in the population is higher.

Besides income, population structure and medical/technological progress, other factors are considered in the literature to explain health care expenditure: percentage of urban population (Leu, 1986; Gerdtham et al., 1992; Wang, 2009, Hosoya, 2014), female labor force participation (Gerdtham et al., 1992; Christiansen et al., 2006; Hosoya, 2014), health care systems characteristics (Gerdtham et al., 1992; Hitiris and Posnett, 1992; Barros, 1998; Christiansen et al., 2006; Mosca, 2007, Wang, 2009; Baltagi and Moscone, 2010; Hosoya, 2014), and health care supply (Gerdtham et al., 1992; Christiansen et al., 2006; Mosca, 2007; Wang, 2009; Magazzino and Mele, 2012; Hosoya, 2014).

To control for the effect of urbanization on the growth rate of real per capita health care expenditure, we use the percentage of urban population (urban_pop_ptot). As urban areas can benefit from economies of scale in terms of the availability of health care resources and lower travel costs, we expect a negative impact on health expenditure.

The percentage of female labor force participation rate (lfp_female), ages $15-64$, is used here as a proxy for the substitution of formal care by informal care, leading to a transition of health care from the family to institutions, and therefore, to higher health care expenditure (Gerdtham et al., 1992; Christiansen et al., 2006). When women participate in the labor force, they have less time to take care of their families (especially children and elderly) when someone is sick or health

\footnotetext{
${ }^{18}$ Note that all sugar variables are stationary in levels (see Table A.2 in Annex), so we will proceed the analysis using levels instead of growth rates. Nonetheless, the robustness of our findings is not affected.
} 
conditions deteriorate. Hence, the family has to spend more in formal/external health care assistance. For example, taking care of elderly was a responsibility of the family, while today this is a role played by various health institutions. Working women also have less time and availability to prepare healthy meals daily, tending to rely on processed fast-food and ready meals, which contribute to the deterioration of the family health, diseases and, consequently, more spending with health care.

The health system characteristics are usually defined by health financing parameters, the kind of provider payment mechanisms and service provision, but the ability to test these variables is limited due to data availability. The better proxy we can use to 'accommodate' those effects is the share of public health care expenditure (hce_pub_texp). It is not clear whether a higher participation of the government in health care expenditure might increase or decrease it, so we abstain from hypothesize a sign for its coefficient. ${ }^{19}$

Regarding health care supply, studies with OECD countries rely on the number of hospital beds or physicians. We control for this effect using the growth rate of the number of hospital beds (hosp_beds_gr), but later - in a sensitivity analysis - we will replace it by the second. We conjecture that the higher is the supply, the more the health care expenditure will grow.

Additionally, we also consider one environmental conditioning: air pollution. Magazzino and Mele (2012) are the first to raise this issue by using the percentage of households who complains about air pollution. We use the percentage of population exposed to levels exceeding WHO guidelines (pollut_pop) and expect that pollution can contribute to an increase in general health problems and increase health care spending.

The results with these new controllers are presented in Table 4 for sugar and natural sweeteners in kilocalories per capita per day (see columns 1-3) and for the respective percentage in total food supply (see columns 4-6). We also report the results for separate samples of OECD and Non-OECD countries.

\section{[Insert Table 4 around here]}

\footnotetext{
${ }^{19}$ See Leu (1986), Culyer(1990) and Gerdtham et al. (1992) for a discussion on the issue. Several other studies have considered this proxy; see, for example, Hitiris and Posnett (1992), Christiansen et al. (2006), Baltagi and Moscone (2010) and Hosoya (2014).
} 
Despite controlling for all those new factors, sugar intake remains an important determinant of health care expenditure, not only for the whole sample but also for the sub-samples of OECD and Non-OECD countries. In particular, when sugar and natural sweeteners availability increases by 10 kilocalories (or one percentage point relatively to total food supply - see column 4 instead), the growth rate of real health care expenditure per capita rises, on average, by around 0.9 (or 2.3) percentage points (p.p.), ceteris paribus. ${ }^{20}$ As the speed of the adjustment is very quick $(0.83=1$ 0.17), the respective long-run impact is only slightly higher (1.1 p.p. or 2.8 p.p., for each case, respectively). Thus, we estimate that, on average, for each additional teaspoon (4 grams or $16 \mathrm{kcal}$ ) of added sugar intake, health care expenditure per capita will grow an additional 1.8 p.p. $(=0.11 * 16)$ in the long-run.

This is a very striking finding as it shows that a small increase in sugar intake (on average) will have a huge impact on health care spending. Like we emphasized in the analysis for diabetes expenditure, this means that the sugar problem is there and that it has reached such a level that additional sugar intake has had severe health consequences, being then reflected in a significant increase in health care expenditure. The level of sugar availability reached such a high level in the time period considered in our sample (1995-2014 - see, for example: Figure 1; Credit Suisse, 2013; IDF, 2015; Morgan Stanley, 2015) that a small increase in sugar availability/intake, during that period, has a large effect on people's health conditions and consequently on health care spending. Therefore, it is quite likely that one more teaspoon of sugar intake, on the top of an already high level of sugar consumption, might have a huge and higher effect on health care spending than it might have had in the past, when the average consumption was lower and when, for that reason, one additional teaspoon of this "poison" would not harm people's health so much... "sola dosis facit venenum", i.e. the dose makes the poison.

This is a problem to which public authorities and governments have to give a closer attention in order to avoid the deterioration of public health, with severe social and economic costs for the society, in general, and constraints concerning the financial resources devoted to health care by the governments, in particular.

\footnotetext{
20 An increase of 10 kilocalories represents approximately an increase of $3.6 \%$ relatively to the mean of kilocalories of sugar and natural sweeteners in the sample (see Table A.1 in Annex). Hence, an increase of $10 \%$ in sugar availability relative to its mean (around 28 kilocalories) will correspond to an immediate rise of about 2.5 p.p. in the growth rate of real total health care expenditure per capita (roughly the same we get when we consider a 1 p.p. increase in the percentage of sugar relatively to total food).
} 
When we look at the groups of OECD and Non-OECD countries separately, we also observe the important role of sugar, but surprisingly the effect is more intense in the group of NonOECD countries. ${ }^{21}$ One possible explanation for this might be the fact of their initial spending on health being very low, but the pressure exerted by a rise in people with health problems have forced them to spend more on health. Thus, like in the convergence models, where poor or developing countries tend to grow faster given their lower initial conditions, these countries will also tend to present a higher growth in health care spending to a (similar) deterioration in health conditions caused by more added sugar in the diet. At the same time, some developing countries have improved their economic conditions allowing them to increase spending more generously in social areas like education, health and culture.

Regarding the control variables, the growth rate of real GDP per capita remains as the main robust determinant: for each 1 p.p. increase in real GDP growth rate, real health care expenditure per capita grows an additional 1.1 p.p., on average. The results for the structure of population are mixed: while the share of young people in the population seems to matter, the percentage of elderly people has not proved to be relevant. Zweifel et al. (1999) and Christiansen et al. (2006) argue that proximity to death can be a better proxy for population aging than pop65abv, but due to lack of data for most of the countries in the sample we cannot consider that variable. ${ }^{22}$

The estimated effect of urbanization for the whole sample is negative, as expected, but not statistically significant. Surprisingly (or not), health care expenditures grow faster in urban areas in OECD countries. This might be an indirect consequence of the deterioration of the quality of life in urban areas in developed countries, not overcome by the expected economies of scale from the availability of health care resources and lower travel costs.

The results for the percentage of female labor force participation are, in general, in line with the literature (Gerdtham et al., 1992; Christiansen et al., 2006): the substitution of formal care by informal care leads to higher health care spending. This effect is particularly intense in the group of less developed countries. The costs involved in that substitution might be higher due to the lack of a proper public health care structure.

\footnotetext{
${ }^{21}$ Note that for the group of OECD countries two lags of the dependent variable are needed to eliminate the second-order autocorrelation.

${ }^{22}$ In the sensitivity analysis presented in Annex (see Table A.4), we consider other proxies for population aging. In particular for males, we find that aging (\% surviving until 65 and life expectancy) has indeed the expected increase in health care spending.
} 
The growth rate of health care spending per capita is not affected by the percentage of public health care expenditure, when we consider the overall sample and Non-OECD countries only. However, a significant negative effect is observed for the group of OECD countries. Culyer (1990) argues that open-financing systems, usually characterized by multiple finance sources (insurance companies) and by fee-for-service remuneration, offer little incentive for providers and little opportunity for financiers to restrain spending. Conversely, closed systems - those characterized by one or few finance agents, public health care services and global budgets for hospitals - can be more efficient in controlling spending. Hence, a higher participation of the government in health care expenditure seems to contribute to a more rational allocation of the resources in the OECD countries. This efficiency in managing health care services can also be considered to explain why no significant effects are found regarding the supply-side (hosp_beds_gr) for this group. Nevertheless, the growth rate of the number of hospital beds has the expected significant positive impact in the whole sample and for Non-OECD countries.

Finally, we confirm that the higher the percentage of population exposed to pollution, the more health care expenditure will grow (for the whole sample and Non-OECD countries). In fact, more pollution will deteriorate general health conditions, putting pressure on health care spending.

In the next set of regressions, we consider some additional variables that are not usually considered in this literature, but - given the aim of this study - may impact on health care expenditure. The results are reported in Table 5, where, once again, only stationary variables are used in the estimations. In the first two regressions we control for (the change in) diabetes and obesity prevalence (diab_nprev and obese_prev). These are two health conditions commonly linked to excessive sugar consumption (Yudkin, 1988; Basu et al., 2013; Lustig et al, 2012; Lustig, 2013). Hence, we test whether, after controlling for these conditions, sugar is still exerting its significant and positive effect on health care spending. The results are clear in confirming it and in showing that those two variables per se have no relevant impact. In fact, similarly to Basu et al. (2013), we can say that when obesity and diabetes prevalence are not included (see column 1 in Table 4) the magnitude of the sugar effect is not substantially amplified, which might suggest that obesity and diabetes do not account for the major part of the important impact that sugar availability/intake has on the growth rate of health care expenditure per capita. ${ }^{23}$

\footnotetext{
${ }^{23}$ These results must be analysed with some care due to some data limitations related to diabetes and obesity prevalence: the number of time periods available for both variables is reduced (especially for diabetes prevalence:
} 


\section{[Insert Table 5 around here]}

To explore this issue in greater detail we also consider here the "net" diabetes and obesity prevalence variables used in the analysis for diabetes expenditure: resid_obese and resid_diab. They represent the part of diabetes and obesity prevalence that is not explained by sugar intake. The results are reported in columns 3 and 4 in Table 5 and they show that "net" obesity prevalence remains insignificant. The way obesity is measured (using the BMI, which is not a consensual measure for obesity), the fact that some obese people might not be unhealthy and some thin people might be (by the reasons pointed by Lustig, 2013, Ch.8) and the lower number of observations may justify this result.

On the contrary, the part of diabetes prevalence not explained by sugar intake is now presenting a significant coefficient. This means that we need to remove the effect of sugar intake on diabetes prevalence - highlighted by Basu et al. (2013) - to uncover the "net" impact of diabetes prevalence on the growth rate of total health care expenditure. Otherwise, the correlation between both regressors is hiding the relevance of diabetes prevalence on health care spending. Thus, we can conclude that "net" diabetes prevalence is not only consistently affecting diabetes expenditure, but also total health care spending. Nevertheless, sugar intake is still playing an important role in both cases.

In the following set of regressions (columns 5-7), we control for total food supply, nutrients (fat, protein, oils), other types of food (cereals, fruits, vegetables, oils, meat, fish) and alcohol. The inclusion of these variables did not affect the results and sugar availability remains with a significant positive coefficient. Only the quantity of fat has proved to have a similar significant impact on health care expenditure. When we disaggregate it in animal fat and oils (and types of foods), we conclude that the effect comes essentially from the consumption of vegetable oils (see columns 7 and 8). ${ }^{24}$ This result may sound controversial, however it is backed up by some recent

2003-2014); they represent estimated values obtained by the IDF (for diabetes prevalence) and WHO (for obesity prevalence); and some missing data had to be generated by linear interpolation.

${ }^{24} \mathrm{We}$ also considered the fraction of each food in total, but results remained unchanged. They are not reported here, but there are available upon request. In Table A.4 in Annex, we provide a sensitivity analysis where the controllers are replaced by other related proxies. Some robustness checks are also reported in Tables A.4 and A.5 in Annex. Table A.5 reports results with different lags for the sugar variable and with two different estimators: a differences-GMM estimator and a fixed-effects estimator. Table A.6 presents some results by regional areas using a fixed effects estimator. In general, the main results and conclusions did not change. 
medical research that shows that vegetable oils may not be as healthy as we think (see: Credit Suisse, 2015; National Obesity Forum, 2016; and the references therein). For example, the National Obesity Forum Report (2016, p. 9) states that "Omega-6 rich vegetable oil (such as sunflower and corn oil), linked to the increased risk of death, coronary heart disease, and cancer in humans cannot be considered safe." Hence, it is quite likely that a rise in the consumption (in some) vegetable oils is linked to an increase in health care expenditure. Nevertheless, as the recommendations on fat consumption and its impact on health are currently subject to a huge debate, more research needs to be done to establish a clear link between fat consumption, health and health care expenditure.

\section{Conclusions}

This study provides evidence to support the thesis that the rise in sugar availability/intake is leading to an increase in health care expenditure. We start by looking at the impact of sugar intake on diabetes expenditure and then on total health care expenditure. We build this macroeconomic analysis upon the standard literature on the determinants of health care expenditure and we estimate a dynamic panel data model over a sample of 156 countries for the period 1995-2014.

The results reported in this paper show that an increase in sugar availability/intake leads to a significant rise in diabetes expenditure (per capita and per diabetic) and in the growth rate of total health care expenditure per capita. We estimate that, on average, in the long-run, for each additional teaspoon of added sugar per person, spending on diabetes per capita will rise $26.8 \%$ and the growth rate of total health care expenditure per capita will augment 1.8 percentage points. This is also observed, with slightly different magnitudes, in a separate analysis for OECD and NonOECD countries. The results are consistent after controlling for income per capita, population, medical/technological progress, urbanization, female participation in the labor force, share of public health expenditure, hospital beds, air pollution, among others.

John Yudkin (Yudkin, 1988), first, and Robert Lusting (Lustig, 2012), later, have very eloquently called the attention to the huge negative impact of sugar consumption on health (incidence of coronary thrombosis, dental caries, obesity, diabetes and liver disease, gout, dyspepsia and some cancers). This study embraces that knowledge and moves a step forward, putting the emphasis on the economic costs of excessive sugar intake. Our findings are striking, as they show that a small increase in sugar intake has a huge impact on diabetes expenditure and total health care spending. Sugar is not only causing the health problems highlighted by Yudkin (1988) 
and Lustig (2012) but also boosting health care expenditures. Public authorities must give a closer attention to this issue in order to avoid the deterioration of public health, severe social and economic costs, and pressure on financial resources devoted to health care. Some countries have already introduced the so called "sugar tax": Denmark, France, Norway, Mexico, and South Africa. More recently, Portugal and the UK announced to do the same in 2017 and 2018, respectively. Although these measures can raise people's awareness to the problem, a more profound work has to be done in terms of information and education.

We must stress that our analysis only takes into account the direct costs of excessive sugar and natural sweeteners intake over diabetes and health care expenditures. We believe that the scenario can be even darker if indirect costs like increased use of health services, loss of productivity, absenteeism, disabilities, and premature mortality are considered. Several studies refer that the indirect costs are a significant part of the problem, maybe even more significant than the direct costs (Credit Swiss, 2013; Kanavos et al., 2012; Morgan Stanley, 2015). However, due to the specific aim of this study and data limitations for most of the countries in our sample, we do not consider indirect costs in this analysis. In future works it would be interesting to conduct a study where those costs are taken into account.

\section{Acknowledgments}

The author acknowledges the helpful research assistance from Eduarda Castro and the willingness of the International Diabetes Federation in sharing the data spreadsheets for diabetes prevalence and expenditure on diabetes. The author is grateful to two anonymous referees for their valuable comments and suggestions to improve the quality of this paper. The author also wishes to thank the financial support provided by the Portuguese Foundation for Science and Technology under the research grant SFRH/BSAB/113588/2015 (partially funded by COMPTE, QREN and FEDER). This paper was written while the author was visiting the Faculty of Economics, University of Cambridge, UK. He is thankful for the facilities provided by this University to develop his research. 


\section{References}

An, Y., Zhao, K., Zhou, R., 2016. Health spending and public pension: evidence from panel data. Applied Economics, 48(11), 987-1004.

Arellano, M., Bond, S., 1991. Some Tests of Specification for Panel Data: Monte Carlo Evidence and an Application to Employment Equations. Review of Economic Studies, 58, 277-297.

Arellano, M., Bover, S., 1995. Another look at the instrumental variable estimation of error components models. Journal of Econometrics, 68, 29-51.

Baltagi, B., 2013. Econometric Analysis of Panel Data, 5th Ed. Chichester, UK. John Wiley \& Sons, Ltd.

Baltagi, B., Moscone, F., 2010. Health care expenditure and income in the OECD reconsidered: Evidence from panel data. Economic Modelling, 27, 804-811.

Barros, P., 1998. The black box of health care expenditure growth determinants. Health Economics, 7 , 533-544.

Basu, S., Yoffe, P., Hills, N., Lustig, R., 2013. The relationship of sugar to population-level diabetes prevalence: An econometric analysis of repeated cross-sectional data. PLoS ONE, 8(2), e57873; doi:10.1371/journal.pone.0057873.

Bates, L., Santerre, R., 2013. Does the U.S. health care sector suffer from Baumol's cost disease? Evidence from the 50 states. Journal of Health Economics 32, 386-391.

Bilgel, F., Tran, K., 2013. The determinants of Canadian provincial health expenditures: evidence from a dynamic panel. Applied Economics, 45, 201-212.

Blomqvist, A. and Carter, R., 1997. Is health-care really a luxury? Journal of Health Economics, 16, 20729.

Blundell R., Bond, S., 1998. Initial conditions and moment restrictions in dynamic panel data models. Journal of Econometrics, 87(1), 115-143.

Bond, S., 2002. Dynamic panel data models: A guide to micro data methods and practice. Portuguese Economic Journal, 1, 141-162.

Bruno, G., 2005a. Estimation and inference in dynamic unbalanced panel-data models with a small number of individuals. Stata Journal, 5(4), 473-500.

Bruno, G., 2005b. Approximating the bias of the LSDV estimator for dynamic unbalanced panel data models. Economics Letters, 87(3), 361-366.

Christiansen, T., Bech, M., Lauridsen, J., Nielsen, P., 2006. Demographic changes and aggregate healthcare expenditure in Europe. ENEPRI Research Report, No. 32. 
Colombier, C., 2012. Drivers of health care expenditure: Does Baumol's cost disease loom large? FiFo Discussion Papers, No. 12-5.

Credit Suisse, 2013. Sugar consumption at a crossroads. Credit Suisse Research Institute.

Credit Suisse, 2015. Fat: The New Health Paradigm. Credit Suisse Research Institute.

Culyer, A., 1990. Cost containment in Europe. In: Health Care Systems in Transition, pp. 29-40. OECD: Paris.

Doornik, J., Arellano, M., Bond, S., 2002. Panel Data Estimation Using DPD for OX: Manuscript. Oxford University.

Gerdtham, U., Lothgren, M., 2000. On stationarity and cointegration of international health expenditure and GDP. Journal of Health Economics 19(4), 461-475.

Gerdtham, U., Jonsson, B., 2000. International comparisons of health expenditure: theory, data and econometric analysis. In: Culyer, A.J., Newhouse, J.P. (Eds.), Handbook of Health Economics, vol. 1A. Elsevier: Amsterdam.

Gerdtham, U., Sogaard, J., Andersson, F., Jonsson, B., 1992. An econometric analysis of health care expenditure: A cross-section study of the OECD countries. Journal of Health Economics, 11, 63-84.

Gerdtham, U., Jönsson, B., MacFarlan, M., Oxley, H., 1998. The determinants of health expenditure in the OECD countries: a pooled data analysis. In Health, the Medical Profession, and Regulation (Ed) P. Zweifel, Kluwer Academic Publishers, Dordrecht.

Gerdtham, U., 1993. The impact of aging on health care expenditure in Sweden. Health Policy, 24, 1-8.

Getzen, T., 1992. Population aging and the growth of health expenditures. Journal of Gerontology, 47, 98-104.

Giannoni, M., Hitiris, T., 2002. The regional impact of health care expenditure: the case of Italy. Applied Economics, 34, 1829-1836.

Hansen, P., King, A., 1996. The determinants of health expenditure: a cointegration approach. Journal of Health Economics, 15, 127-137.

Hartwig, J., 2008. What drives health care expenditure? Baumol's model of 'unbalanced growth' revisited. Journal of Health Economics, 27, 603-623.

Hartwig, J., Sturm, J., 2014. Robust determinants of health care expenditure growth. Applied Economics, 46(36), 4455-4474.

Herwartz, H., Theilen, B., 2003. The determinants of health care expenditure: testing pooling restrictions in small samples. Health Economics, 12: 113-124. 
Herwartz, H., Theilen, B., 2010. The determinants of health-care expenditure: New results from semiparametric estimation. Health Economics, 19, 964-978.

Hitiris, T., Posnett, J., 1992. The determinants and effects of health expenditure in developed countries. Journal of Health Economics, 11, 173-181.

Hosoya, K., 2014. Determinants of health expenditures: Stylized facts and a new signal. Modern Economy, 5, 1171-1180.

IDF, 2015. Diabetes Atlas, 7th Ed. International Diabetes Federation.

Jiang, Y., Pan, Y., Rhea1, P., Tan, L., Gagea, M., Cohen, L., Fischer, S., Yang, P., 2016. A Sucrose-

Enriched Diet Promotes Tumorigenesis in Mammary Gland in Part through the 12Lipoxygenase Pathway. Cancer Research, 76, 24-29.

Kanavos, P., Aardweg, S., Schurer, W., 2012. Diabetes expenditure, burden of disease and management in 5 EU countries. LSE Health Report, London School of Economics.

Leu, R., 1986. The public-private mix and international health care costs. In: Culyer, A.J., Jonsson, B. (Eds.), Public and Private Health Care Services: Complementarities and Conflicts. Basil Blackwell: Oxford.

Lustig, R., Nguyen, S., 2010. Just a spoonful of sugar helps the blood pressure to go up. Expert Review of Cardiovascular Therapy, 8(11), 1497-1499.

Lustig, R., 2013. Fat Chance: Beating the odds against sugar, processed food, obesity, and disease. Penguin Group: London.

Lustig, R., Schmidt, L., Brindis, C., 2012. The toxic truth about sugar. Nature, 482, $27-29$.

Morgan Stanley, 2015. The bitter aftertaste of sugar. Morgan Stanley Research, 18 March.

Magazzino, C., Mele, M., 2012. The Determinants of health expenditure in Italian regions. International Journal of Economics and Finance, 4(3), 61-72.

Martin, J., González, M., García, M., 2011. Review of the literature on the determinants of healthcare expenditure. Applied Economics, 43, 19-46.

McCoskey, S., Selden, T., 1998. Health care expenditures and GDP: panel data unit root test results. Journal of Health Economics 17(3), 369-376.

Medeiros, J., Schwierz, C., 2013. Estimating the drivers and projecting long-term public health expenditure in the European Union: Baumol's "cost-disease" revisited. European Economy Economic Papers, No. 507.

Mosca, I., 2007. Decentralization as a determinant of health care expenditure: Empirical analysis for OECD countries. Applied Economics Letters, 14(7), 511-515. 
National Obesity Forum, 2015. Eat fat, cut the carbs and avoid snacking to reverse obesity and type-2 diabetes. Issued jointly with the Public Health Collaboration, United Kingdom, http://www.nationalobesityforum.org.uk/ and https://phcuk.org/.

Null, G., 2014. Sugar: Killing us Sweetly. Staggering Health Consequences of Sugar on Health of Americans. Global Research, http://www.globalresearch.ca/sugar-killing-us-sweetly/5367250.

Newhouse, J., 1977. Medical-care expenditure: A cross-national survey. Journal of Human Resources, $12(1), 115-125$.

Or, Z., 2000. Determinants of health outcomes in industrialised countries: a pooled, cross-country, timeseries analysis. OECD Economic Studies, No. 30(1), 53-77.

Panopoulou, E., Pantelidis, T., 2012. Convergence in per capita health expenditures and health outcomes in the OECD countries. Applied Economics, 44, 3909-3920.

Parkin, D., McGuire, A., Yule, B., 1987. Aggregate health care expenditures and national income: is health care a luxury good? Journal of Health Economics, 6(2), 109-127.

Roberts, J., 1999. Sensitivity of elasticity estimates for OECD health care spending: analysis of a dynamic heterogeneous data field. Health Economics, 8(5), 459-472.

Roodman, D., 2009a. How to do xtabond2: An introduction to difference and system GMM in Stata. Stata Journal, 9(1), 86-136.

Roodman, D. M. 2009b. A note on the theme of too many instruments. Oxford Bulletin of Economics and Statistics, 71, 135-158.

Xu, K., Saksena, P., Holly, A., 2011. The determinants of health expenditure: A country level panel data analysis. WHO Results for Development Institute Working Paper.

Wang, Z., 2009. The determinants of health expenditures: evidence from US state-level data. Applied Economics, 41, 429-435.

Wu, P., Liu, S., Pan, S., 2014. Nonlinear relationship between health care expenditure and its determinants: a panel smooth transition regression model. Empirica, 41, 713-729.

Yudkin, J., 1988. Pure, White and Deadly. Penguin Group: London. [First published in 1972; Republished in 2012 under the title "Pure, White and Deadly: How sugar is killing us and what we can do to stop it.”]

Zweifel, P., Felder, S., Meier, M., 1999. Ageing of population and health care expenditure: a red herring? Health Economics, 8, 485-496. 
Tables

Table 1 - Description of the variables and sources

\begin{tabular}{|c|c|c|c|}
\hline Variable & Description & Source & Mean \\
\hline rdiab_exp_pc & Real health expenditure for diabetes per capita (constant 2010 USD). & IDF & 85.05 \\
\hline rdiab_exp_ppd & Mean diabetes related expenditure per person with diabetes (constant 2010 USD). & IDF & 909.00 \\
\hline rhcepc & Real total health care expenditure per capita (constant 2010 USD). & WDI & 894.82 \\
\hline rhcepc_gr & Annual growth rate of real health care expenditure per capita (in \%). & Own calculation & 0.40 \\
\hline sugar_swt_kcal & Sugar and natural sweeteners food supply, in kilocalories per person per day. & FAOSTAT & 279.21 \\
\hline sugar_ref_kcal & Sugar refined food supply, in kilocalories per person per day. & FAOSTAT & 255.14 \\
\hline sugar_swt_gcd & Sugar and natural sweeteners food supply/quantity, in grams per person per day. & FAOSTAT & 81.11 \\
\hline sugar_ptot_kcal & $\%$ of sugar and natural sweeteners kilocalories in total food per person per day. & FAOSTAT & 9.98 \\
\hline sugar_swt_kcal_gr & Annual growth rate of sugar and sweeteners food supply (in \%). & Own calculation & 0.86 \\
\hline rgdppc & Real GDP per capita (constant 2010 USD). & WDI & 11093.1 \\
\hline rgdppc_gr & Annual growth rate of real GDP per capita (in \%). & WDI & 2.54 \\
\hline рор014 & $\%$ of population aged $0-14$ years. & WDI & 30.91 \\
\hline pop65abv & $\%$ population aged 65 and above. & WDI & 7.28 \\
\hline urban_pop_ptot & $\%$ of urban population. & WDI & 56.09 \\
\hline lfp_female & Labor force participation rate, female (\% of female population ages $15-64)$. & WDI & 56.25 \\
\hline hce_pub_texp & Public health care expenditure ( $\%$ of total health care expenditure). & WDI & 57.26 \\
\hline hosp_beds & Number of hospital beds per 1000 inhabitants. & WDI & 3.43 \\
\hline hosp_beds_gr & Annual growth rate of hospital beds (in \%). & WDI & -1.54 \\
\hline pollut_pop & Air pollution: \% population exposed to levels exceeding WHO guidelines. & WDI & 73.11 \\
\hline diab_nprev & Diabetes national prevalence ( $\%$ adult population, $20-79$ years). & IDF & 7.29 \\
\hline obese_prev & Percentage of obese adults ( 18 years and above), i.e. with BMI $>=30 \mathrm{Kg} / \mathrm{m}^{2}$. & WHO & 16.13 \\
\hline total_kcal & Total food supply, in kilocalories per person per day. & FAOSTAT & 2713.96 \\
\hline total_fat_gcd & Total fat supply/quantity, in grams per person per day. & FAOSTAT & 80.09 \\
\hline total_prot_gcd & Total protein supply/quantity, in grams per person per day. & FAOSTAT & 76.26 \\
\hline anim_prod_fat_gcd & Animal products fat supply/quantity, in grams per person per day. & FAOSTAT & 36.42 \\
\hline oils_gcd & Vegetable oils and oil crops supply/quantity, in grams per person per day. & FAOSTAT & 57.62 \\
\hline anim_prod_prot_gcd & Animal products protein supply/quantity, in grams per person per day. & FAOSTAT & 34.13 \\
\hline cereal_kcal & Cereals food supply, in kilocalories per person per day. & FAOSTAT & 1097.82 \\
\hline fruit_kcal & Fruits food supply, in kilocalories per person per day. & FAOSTAT & 102.86 \\
\hline vegs_kcal & Vegetables food supply, in kilocalories per person per day. & FAOSTAT & 55.65 \\
\hline oils_kcal & Vegetable oils and oil crops food supply, in kilocalories per person per day. & FAOSTAT & 317.99 \\
\hline meat_kcal & Meat food supply, in kilocalories per person per day. & FAOSTAT & 217.32 \\
\hline fish_kcal & Fish and seafood food supply, in kilocalories per person per day. & FAOSTAT & 35.91 \\
\hline alcohol_kcal & Alcoholic beverages food supply, in kilocalories per person per day. & FAOSTAT & 76.88 \\
\hline unemp_rate & Unemployment rate (\% of total labor force) & WDI & 8.86 \\
\hline surv65_fem & Survival to age 65 , female ( $\%$ of cohort). & WDI & 74.32 \\
\hline surv65_male & Survival to age 65 , male ( $\%$ of cohort). & WDI & 65.16 \\
\hline life_exp_fem & Life expectancy at birth, female (in years). & WDI & 70.80 \\
\hline life_exp_male & Life expectancy at birth, male (in years). & WDI & 66.00 \\
\hline pop_dens & Population density (people per square km of land area). & WDI & 376.70 \\
\hline lfp_ratio_fm & Ratio of female to male labor force participation rate (in \%). & WDI & 68.43 \\
\hline hce_pub_gdp & Public health care expenditure (\% of GDP). & WDI & 3.67 \\
\hline physicians & Number of physicians per 1000 inhabitants. & WDI & 1.57 \\
\hline pollut_expos & Air pollution: mean annual exposure (micrograms per cubic meter). & WDI & 17.85 \\
\hline
\end{tabular}

Sources: International Diabetes Federation (IDF), Diabetes Atlas, several issues (www.diabetesatlas.org). Food and Agriculture Organization of the United Nations (FAOSTAT), Food Supply Database (http://faostat.fao.org/site/345/default.aspx). World Bank, World Development Indicators (WDI) Database (http://data.worldbank.org/data-catalog/world-development-indicators). World Health Organization (WHO) Global Infobase (https://apps.who.int/infobase/). 
Table 2. Diabetes expenditure

\begin{tabular}{|c|c|c|c|c|c|c|c|c|c|}
\hline \multirow[t]{2}{*}{ Dep.Variable: } & \multicolumn{5}{|c|}{ lnrdiab_exp_pc } & \multicolumn{4}{|c|}{ lnrdiab_exp_ppd } \\
\hline & $\begin{array}{l}\text { All } \\
\text { (1) }\end{array}$ & $\begin{array}{l}\text { All } \\
\text { (2) }\end{array}$ & $\begin{array}{l}\text { All } \\
\text { (3) } \\
\end{array}$ & $\begin{array}{c}\text { OECD } \\
(4)\end{array}$ & $\begin{array}{c}\text { Non-OECD } \\
(5)\end{array}$ & $\begin{array}{l}\text { All } \\
\text { (6) }\end{array}$ & $\begin{array}{l}\text { All } \\
\text { (7) }\end{array}$ & $\begin{array}{c}\text { OECD } \\
(8)\end{array}$ & $\begin{array}{c}\text { Non-OECD } \\
(9)\end{array}$ \\
\hline L.lnrdiab_exp_pc & $\begin{array}{c}0.4648 * * \\
(0.1883)\end{array}$ & $\begin{array}{c}0.4727 * * * \\
(0.1575)\end{array}$ & $\begin{array}{c}0.4729 * * * \\
(0.1606)\end{array}$ & $\begin{array}{l}0.1821^{*} \\
(0.1075)\end{array}$ & $\begin{array}{c}0.6686^{* * * *} \\
(0.1331)\end{array}$ & & & & \\
\hline L.lnrdiab_exp_ppd & & & & & & $\begin{array}{c}0.7998 * * * \\
(0.1126)\end{array}$ & $\begin{array}{c}0.7948 * * * * \\
(0.1106)\end{array}$ & $\begin{array}{c}0.4781 * * \\
(0.1891)\end{array}$ & $\begin{array}{c}0.9291 * * * \\
(0.0361)\end{array}$ \\
\hline lnsugar_swt_kcal & $\begin{array}{c}2.9522 * * \\
(1.1480)\end{array}$ & $\begin{array}{c}2.3674 * * \\
(0.9415)\end{array}$ & $\begin{array}{c}2.5071 * * \\
(1.0525)\end{array}$ & $\begin{array}{c}1.8206 * * * \\
(0.6833)\end{array}$ & $\begin{array}{l}1.2941 * * \\
(0.6321)\end{array}$ & $\begin{array}{c}0.8839 * * \\
(0.3753)\end{array}$ & $\begin{array}{c}0.8327 * * \\
(0.3685)\end{array}$ & $\begin{array}{l}0.5596^{*} \\
(0.3029)\end{array}$ & $\begin{array}{l}0.4310^{*} \\
(0.2601)\end{array}$ \\
\hline $\ln r g d p p c$ & $\begin{array}{l}-0.2107 \\
(0.4814)\end{array}$ & & & & & & & & \\
\hline$r g d p p c \_g r$ & & $\begin{array}{c}0.0142 * * \\
(0.0068)\end{array}$ & $\begin{array}{c}0.0140 * * \\
(0.0069)\end{array}$ & $\begin{array}{c}0.0064 \\
(0.0080)\end{array}$ & $\begin{array}{c}0.0066 \\
(0.0054)\end{array}$ & $\begin{array}{c}0.0009 \\
(0.0045)\end{array}$ & $\begin{array}{c}0.0009 \\
(0.0044)\end{array}$ & $\begin{array}{c}0.0049 \\
(0.0076)\end{array}$ & $\begin{array}{l}-0.0044 \\
(0.0032)\end{array}$ \\
\hline рор014 & $\begin{array}{c}0.0616 \\
(0.0525)\end{array}$ & $\begin{array}{c}0.0513 \\
(0.0574)\end{array}$ & $\begin{array}{c}0.0608 \\
(0.0613)\end{array}$ & $\begin{array}{c}0.1178 * * \\
(0.0588)\end{array}$ & $\begin{array}{c}0.0191 \\
(0.0417)\end{array}$ & $\begin{array}{c}0.0310 \\
(0.0210)\end{array}$ & $\begin{array}{c}0.0284 \\
(0.0216)\end{array}$ & $\begin{array}{c}0.0669 \\
(0.0460)\end{array}$ & $\begin{array}{c}0.0167 \\
(0.0159)\end{array}$ \\
\hline pop65abv & $\begin{array}{c}0.1295^{* *} \\
(0.0563)\end{array}$ & $\begin{array}{l}0.0988^{*} \\
(0.0516)\end{array}$ & $\begin{array}{c}0.1019 * * \\
(0.0497)\end{array}$ & $\begin{array}{c}0.2035^{* * *} * \\
(0.0625)\end{array}$ & $\begin{array}{c}0.0151 \\
(0.0316)\end{array}$ & $\begin{array}{c}0.0462 * * \\
(0.0222)\end{array}$ & $\begin{array}{c}0.0452^{* *} \\
(0.0219)\end{array}$ & $\begin{array}{l}0.1036^{*} \\
(0.0540)\end{array}$ & $\begin{array}{c}0.0120 \\
(0.0118)\end{array}$ \\
\hline D.diab_nprev & & & $\begin{array}{c}0.0976 * * * \\
(0.0278)\end{array}$ & $\begin{array}{c}0.0076 \\
(0.0362)\end{array}$ & $\begin{array}{c}0.0972 * * \\
(0.0416)\end{array}$ & & $\begin{array}{l}-0.0166 \\
(0.0184)\end{array}$ & $\begin{array}{l}-0.0457 \\
(0.0300)\end{array}$ & $\begin{array}{l}-0.0281 \\
(0.0223)\end{array}$ \\
\hline trend & $\begin{array}{c}0.0735 * * * \\
(0.0186)\end{array}$ & $\begin{array}{c}0.0707 * * * \\
(0.0197)\end{array}$ & $\begin{array}{c}0.0733 * * * \\
(0.0204)\end{array}$ & $\begin{array}{c}0.0809 * * * \\
(0.0150)\end{array}$ & $\begin{array}{c}0.0562 * * * \\
(0.0137)\end{array}$ & $\begin{array}{c}0.0495 * * * \\
(0.0081)\end{array}$ & $\begin{array}{c}0.0487 * * * \\
(0.0084)\end{array}$ & $\begin{array}{c}0.0455^{* * * *} \\
(0.0102)\end{array}$ & $\begin{array}{c}0.0516 * * * \\
(0.0078)\end{array}$ \\
\hline \# Observations & 1254 & 1255 & 1255 & 268 & 987 & 1255 & 1255 & 268 & 987 \\
\hline \# Countries & 154 & 155 & 155 & 34 & 121 & 155 & 155 & 34 & 121 \\
\hline \# Instruments & 121 & 120 & 130 & 124 & 130 & 120 & 130 & 124 & 130 \\
\hline Hansen-test & 0.113 & 0.119 & 0.128 & 1.000 & 0.571 & 0.036 & 0.079 & 1.000 & 0.519 \\
\hline Diff.-Hansen & 0.125 & 0.089 & 0.103 & 1.000 & 0.459 & 0.026 & 0.055 & 1.000 & 0.430 \\
\hline $\mathrm{AR}(1)$ & 0.037 & 0.032 & 0.035 & 0.201 & 0.027 & 0.009 & 0.009 & 0.188 & 0.007 \\
\hline $\mathrm{AR}(2)$ & 0.948 & 0.714 & 0.676 & 0.124 & 0.166 & 0.517 & 0.505 & 0.146 & 0.132 \\
\hline
\end{tabular}

Notes: See Figure 2 and Table 1. Two-step system-GMM estimations for dynamic panel data models using robust standard errors corrected for finite samples (standard errors are reported in parentheses); significance levels at which the null hypothesis is rejected: ***, $1 \% ; * *, 5 \%$, and $*, 10 \%$. The lag of the respective dependent variable, the growth of real GDP per capita (the log of rgdppc in the first regression) and the log of sugar and sweeteners availability are treated as endogenous in the GMM estimations; the respective lagged values and the other explanatory variables are used as instruments in the first-difference equation and their first-differences are used in the levels equation; they were collapsed to avoid the problem of having too many instruments. The Hansen-test reports the $p$-value for the null hypothesis of instrument validity; the difference-in-Hansen test assesses the validity of the GMM instruments of the levels equation. The values reported for $\operatorname{AR}(1)$ and $\operatorname{AR}(2)$ are the $p$-values of the Arellano-Bond tests for first and second order auto-correlated disturbances in the first differences equations. Separate estimations for OECD and NonOECD countries are reported, respectively, in columns (4) and (8), and (5) and (9). 
Table 3. Basic specifications for sugar sensitivity on health care expenditure

\begin{tabular}{|c|c|c|c|c|c|c|c|}
\hline & $(1)$ & $(2)$ & (3) & (4) & $(5)$ & (6) & $(7)$ \\
\hline L.lnrhcepc & $\begin{array}{c}0.9411 * * * \\
(0.0552)\end{array}$ & & & & & & \\
\hline L2.lnrhcepc & $\begin{array}{c}-0.2208 * * * \\
(0.0329)\end{array}$ & & & & & & \\
\hline L.rhcepc_gr & & $\begin{array}{c}0.1703 * * * \\
(0.0467)\end{array}$ & $\begin{array}{c}0.1771 * * * \\
(0.0483)\end{array}$ & $\begin{array}{c}0.1754 * * * \\
(0.0495)\end{array}$ & $\begin{array}{c}0.1782 * * * \\
(0.0495)\end{array}$ & $\begin{array}{c}0.1806^{* * * *} \\
(0.0480)\end{array}$ & $\begin{array}{c}0.1758 * * * \\
(0.0507)\end{array}$ \\
\hline lnsugar_swt_kcal & $\begin{array}{c}0.2568 * * \\
(0.1146)\end{array}$ & $\begin{array}{l}21.1031 * * \\
(9.4556)\end{array}$ & & & & & \\
\hline sugar_swt_kcal_gr & & & $\begin{array}{c}0.0798 * * \\
(0.0346)\end{array}$ & & & & \\
\hline sugar_swt_kcal & & & & $\begin{array}{c}0.0926^{* *} \\
(0.0383)\end{array}$ & & & \\
\hline sugar_ptot_kcal & & & & & $\begin{array}{c}3.1241 * * \\
(1.2735)\end{array}$ & & \\
\hline sugar_ref_kcal & & & & & & $\begin{array}{c}0.0670 * * \\
(0.0315)\end{array}$ & \\
\hline sugar_swt_gcd & & & & & & & $\begin{array}{c}0.2504 * * \\
(0.1035)\end{array}$ \\
\hline $\ln r g d p p c$ & $\begin{array}{l}0.1284 * \\
(0.0775)\end{array}$ & & & & & & \\
\hline$r g d p p c \_g r$ & & $\begin{array}{c}1.0609 * * * \\
(0.1450)\end{array}$ & $\begin{array}{c}0.9569 * * * \\
(0.1438)\end{array}$ & $\begin{array}{c}1.0260 * * * \\
(0.1391)\end{array}$ & $\begin{array}{c}1.0353 * * * \\
(0.1397)\end{array}$ & $\begin{array}{c}1.0502 * * * \\
(0.1409)\end{array}$ & $\begin{array}{c}1.0593 * * * \\
(0.1400)\end{array}$ \\
\hline рор014 & $\begin{array}{c}0.0029 \\
(0.0063)\end{array}$ & $\begin{array}{l}1.0866^{*} \\
(0.5619)\end{array}$ & $\begin{array}{c}0.7067 \\
(0.6418)\end{array}$ & $\begin{array}{c}0.8950 * * \\
(0.4456)\end{array}$ & $\begin{array}{c}0.9146 * * \\
(0.4023)\end{array}$ & $\begin{array}{l}0.5020^{*} \\
(0.2765)\end{array}$ & $\begin{array}{c}0.6841 * * \\
(0.3479)\end{array}$ \\
\hline pop65abv & $\begin{array}{c}0.0292 * * * \\
(0.0066)\end{array}$ & $\begin{array}{c}0.7552 \\
(0.4994)\end{array}$ & $\begin{array}{c}0.8074 \\
(0.9843)\end{array}$ & $\begin{array}{c}0.5056 \\
(0.4097)\end{array}$ & $\begin{array}{c}0.9195 * * \\
(0.4635)\end{array}$ & $\begin{array}{c}0.3025 \\
(0.2708)\end{array}$ & $\begin{array}{c}0.2993 \\
(0.3061)\end{array}$ \\
\hline trend & $\begin{array}{c}0.0067 * * * \\
(0.0018)\end{array}$ & $\begin{array}{c}0.8345 * * * \\
(0.1713)\end{array}$ & $\begin{array}{c}0.5945^{* * * *} \\
(0.0883)\end{array}$ & $\begin{array}{c}0.8129 * * * \\
(0.1697)\end{array}$ & $\begin{array}{c}0.9070 * * * \\
(0.1931)\end{array}$ & $\begin{array}{c}0.7567 * * * \\
(0.1419)\end{array}$ & $\begin{array}{c}0.7426 * * * \\
(0.1356)\end{array}$ \\
\hline \# Observations & 2212 & 2224 & 2222 & 2224 & 2224 & 2224 & 2222 \\
\hline \# Countries & 154 & 156 & 156 & 156 & 156 & 156 & 156 \\
\hline \# Instruments & 130 & 127 & 126 & 127 & 127 & 127 & 127 \\
\hline Hansen-test & 0.130 & 0.298 & 0.287 & 0.310 & 0.263 & 0.272 & 0.286 \\
\hline Diff.-Hansen & 0.116 & 0.251 & 0.260 & 0.188 & 0.238 & 0.267 & 0.243 \\
\hline $\mathrm{AR}(1)$ & 0.000 & 0.000 & 0.000 & 0.000 & 0.000 & 0.000 & 0.000 \\
\hline $\mathrm{AR}(2)$ & 0.751 & 0.266 & 0.284 & 0.270 & 0.274 & 0.293 & 0.272 \\
\hline
\end{tabular}

Notes: See Table 1. Two-step system-GMM estimations for dynamic panel data models using robust standard errors corrected for finite samples (standard errors are reported in parentheses); significance levels at which the null hypothesis is rejected: $* * *, 1 \% ; * *, 5 \%$, and $*, 10 \%$. The lag of the respective dependent variable, the growth of real GDP per capita and the sugar and sweeteners availability are treated as endogenous in the GMM estimations (except in regression (1), where logs are used); the respective lagged values and the other explanatory variables are used as instruments in the first-difference equation and their first-differences are used in the levels equation; they were collapsed to avoid the problem of having too many instruments. The Hansen-test reports the $p$-value for the null hypothesis of instrument validity; the difference-in-Hansen test assesses the validity of the GMM instruments of the levels equation. The values reported for $\operatorname{AR}(1)$ and $\operatorname{AR}(2)$ are the $p$-values of the Arellano-Bond tests for first and second order auto-correlated disturbances in the first differences equations. The dependent variable in regression (1) is lnrhcepc, while in the other regressions id rhcepc_gr. 
Table 4. Baseline specifications for the impact of sugar on health care expenditure

\begin{tabular}{|c|c|c|c|c|c|c|}
\hline \multirow[t]{2}{*}{ Sugar variable: } & \multicolumn{3}{|c|}{ Sugar availability in kilocalories } & \multicolumn{3}{|c|}{ Sugar availability as $\%$ of total food supply } \\
\hline & $\begin{array}{l}\text { All } \\
(1) \\
\end{array}$ & $\begin{array}{l}\text { OECD } \\
(2)\end{array}$ & $\begin{array}{c}\text { Non-OECD } \\
(3) \\
\end{array}$ & $\begin{array}{l}\text { All } \\
(4) \\
\end{array}$ & $\begin{array}{c}\text { OECD } \\
(5)\end{array}$ & $\begin{array}{c}\text { Non-OECD } \\
(6)\end{array}$ \\
\hline L.rhcepc_gr & $\begin{array}{c}0.1653 * * * \\
(0.0531)\end{array}$ & $\begin{array}{c}0.3302 * * * \\
(0.0631)\end{array}$ & $\begin{array}{c}0.1524 * * * \\
(0.0520)\end{array}$ & $\begin{array}{c}0.1699 * * * \\
(0.0522)\end{array}$ & $\begin{array}{c}0.3243 * * * \\
(0.0614)\end{array}$ & $\begin{array}{c}0.1474 * * * \\
(0.0522)\end{array}$ \\
\hline L2.rhcepc_gr & & $\begin{array}{c}-0.2018 * * * \\
(0.0441)\end{array}$ & & & $\begin{array}{c}-0.2000 * * * \\
(0.0434)\end{array}$ & \\
\hline sugar_swt_kcal & $\begin{array}{c}0.0882 * * * \\
(0.0335)\end{array}$ & $\begin{array}{c}0.0795 * * \\
(0.0400)\end{array}$ & $\begin{array}{c}0.1492 * * * \\
(0.0562)\end{array}$ & & & \\
\hline sugar_ptot_kcal & & & & $\begin{array}{c}2.3027 * * \\
(1.1127)\end{array}$ & $\begin{array}{c}2.6260 * * \\
(1.3157)\end{array}$ & $\begin{array}{c}4.1526^{* *} \\
(1.8900)\end{array}$ \\
\hline$r g d p p c \_g r$ & $\begin{array}{c}1.1156 * * * \\
(0.1571)\end{array}$ & $\begin{array}{c}1.1428 * * * \\
(0.2548)\end{array}$ & $\begin{array}{c}1.1850 * * * \\
(0.1920)\end{array}$ & $\begin{array}{c}1.1197 * * * \\
(0.1487)\end{array}$ & $\begin{array}{c}1.1661 * * * \\
(0.2566)\end{array}$ & $\begin{array}{c}1.1211 * * * \\
(0.1670)\end{array}$ \\
\hline рор014 & $\begin{array}{c}0.6968 * * \\
(0.2833)\end{array}$ & $\begin{array}{l}3.9109 * * \\
(1.8861)\end{array}$ & $\begin{array}{c}0.7309 \\
(0.5116)\end{array}$ & $\begin{array}{c}0.5996 * * \\
(0.3026)\end{array}$ & $\begin{array}{c}4.0365^{* *} \\
(1.9245)\end{array}$ & $\begin{array}{l}0.8226^{*} \\
(0.4626)\end{array}$ \\
\hline pop65abv & $\begin{array}{c}0.1391 \\
(0.3561)\end{array}$ & $\begin{array}{l}-0.2851 \\
(1.8165)\end{array}$ & $\begin{array}{l}-0.9707 \\
(0.8120)\end{array}$ & $\begin{array}{c}0.3917 \\
(0.3511)\end{array}$ & $\begin{array}{l}-0.5708 \\
(1.9757)\end{array}$ & $\begin{array}{l}-0.4098 \\
(0.5728)\end{array}$ \\
\hline urban_pop_ptot & $\begin{array}{l}-0.1196 \\
(0.0846)\end{array}$ & $\begin{array}{c}2.3242 * * * \\
(0.8417)\end{array}$ & $\begin{array}{l}-0.1910 \\
(0.1395)\end{array}$ & $\begin{array}{l}-0.0723 \\
(0.0723)\end{array}$ & $\begin{array}{c}2.4688 * * * \\
(0.8989)\end{array}$ & $\begin{array}{l}-0.1653 \\
(0.1344)\end{array}$ \\
\hline lfp_female & $\begin{array}{c}0.1505^{* *} \\
(0.0722)\end{array}$ & $\begin{array}{c}-0.7489 \\
(0.5198)\end{array}$ & $\begin{array}{c}0.3163 * * \\
(0.1393)\end{array}$ & $\begin{array}{l}0.1302 * \\
(0.0765)\end{array}$ & $\begin{array}{l}-0.9127^{*} \\
(0.4918)\end{array}$ & $\begin{array}{l}0.2571 * \\
(0.1439)\end{array}$ \\
\hline hce_pub_texp & $\begin{array}{c}0.0452 \\
(0.0541)\end{array}$ & $\begin{array}{c}-0.9421 * * \\
(0.4073)\end{array}$ & $\begin{array}{l}-0.0496 \\
(0.1126)\end{array}$ & $\begin{array}{c}0.0816 \\
(0.0512)\end{array}$ & $\begin{array}{c}-0.9179 * * \\
(0.4238)\end{array}$ & $\begin{array}{c}0.0331 \\
(0.0970)\end{array}$ \\
\hline$h o s p \_b e d s \_g r$ & $\begin{array}{c}0.0445 * * \\
(0.0199)\end{array}$ & $\begin{array}{c}0.0233 \\
(0.1000)\end{array}$ & $\begin{array}{c}0.0475^{* *} \\
(0.0201)\end{array}$ & $\begin{array}{c}0.0479 * * \\
(0.0196)\end{array}$ & $\begin{array}{c}0.0154 \\
(0.0936)\end{array}$ & $\begin{array}{c}0.0403 * * \\
(0.0174)\end{array}$ \\
\hline pollut_pop & $\begin{array}{c}0.0799 * * \\
(0.0346)\end{array}$ & $\begin{array}{c}0.2162 \\
(0.1986)\end{array}$ & $\begin{array}{l}0.1160 * \\
(0.0604)\end{array}$ & $\begin{array}{l}0.0901 * * \\
(0.0392)\end{array}$ & $\begin{array}{c}0.2269 \\
(0.1818)\end{array}$ & $\begin{array}{l}0.1390 * * \\
(0.0658)\end{array}$ \\
\hline trend & $\begin{array}{c}0.8317 * * * \\
(0.1350)\end{array}$ & $\begin{array}{c}0.1093 \\
(0.5017)\end{array}$ & $\begin{array}{c}0.8371 * * * \\
(0.2107)\end{array}$ & $\begin{array}{c}0.8703 * * * \\
(0.1620)\end{array}$ & $\begin{array}{c}0.1823 \\
(0.5377)\end{array}$ & $\begin{array}{c}1.0225^{* * * *} \\
(0.2600)\end{array}$ \\
\hline \# Observations & 1987 & 415 & 1506 & 1987 & 415 & 1506 \\
\hline \# Countries & 151 & 33 & 117 & 151 & 33 & 117 \\
\hline \# Instruments & 129 & 73 & 129 & 129 & 73 & 129 \\
\hline Hansen-test & 0.314 & 0.999 & 0.791 & 0.198 & 0.999 & 0.834 \\
\hline Diff.-Hansen & 0.280 & 0.998 & 0.703 & 0.195 & 0.996 & 0.725 \\
\hline $\operatorname{AR}(1)$ & 0.000 & 0.000 & 0.000 & 0.000 & 0.000 & 0.000 \\
\hline $\operatorname{AR}(2)$ & 0.290 & 0.570 & 0.494 & 0.299 & 0.471 & 0.450 \\
\hline
\end{tabular}

Notes: See Table 1. Two-step system-GMM estimations for dynamic panel data models using robust standard errors corrected for finite samples (standard errors are reported in parentheses); significance levels at which the null hypothesis is rejected: $* * *, 1 \%$; **, $5 \%$, and $*, 10 \%$. The lag of the dependent variable, the growth of real GDP per capita and the sugar and sweeteners availability are treated as endogenous in the GMM estimations; the respective lagged values and the other explanatory variables are used as instruments in the first-difference equation and their first-differences are used in the levels equation; they were collapsed to avoid the problem of having too many instruments. The Hansen-test reports the $p$-value for the null hypothesis of instrument validity; the difference-inHansen test assesses the validity of the GMM instruments of the levels equation. The values reported for AR(1) and $\mathrm{AR}(2)$ are the $p$-values of the Arellano-Bond tests for first and second order auto-correlated disturbances in the first differences equations. Separate estimations for OECD and Non-OECD countries are reported, respectively, in columns (2) and (5), and (3) and (6). 
Table 5. Additional variables: diseases and foods

\begin{tabular}{|c|c|c|c|c|c|c|c|c|c|}
\hline & $(1)$ & (2) & (3) & (4) & (5) & (6) & $(7)$ & (8) & (9) \\
\hline \multirow[t]{2}{*}{ L.rhcepc_gr } & 0.0561 & $0.1213 * *$ & $0.1104 *$ & $0.1460 * * *$ & $0.1670 * * *$ & $0.1654 * * *$ & $0.1693 * * *$ & 0.1635 *** & 0.1650 **** \\
\hline & $(0.0747)$ & $(0.0590)$ & $(0.0613)$ & $(0.0556)$ & $(0.0541)$ & $(0.0528)$ & $(0.0526)$ & $(0.0542)$ & $(0.0527)$ \\
\hline \multirow[t]{2}{*}{ sugar_swt_kcal } & $0.0669 * *$ & $0.0606 * *$ & $0.0657 * *$ & $0.0671 * *$ & $0.0694 * *$ & & & $0.0838 * *$ & $0.0824 * *$ \\
\hline & $(0.0329)$ & $(0.0293)$ & $(0.0318)$ & $(0.0322)$ & $(0.0322)$ & & & $(0.0351)$ & $(0.0323)$ \\
\hline sugar_swt_gcd & & & & & & $\begin{array}{c}0.2524 * * * \\
(0.0936)\end{array}$ & $\begin{array}{c}0.2429 * * * \\
(0.0894)\end{array}$ & & \\
\hline \multirow[t]{2}{*}{$r g d p p c \_g r$} & $1.1076 * * *$ & $1.1070 * * *$ & $0.9526 * * *$ & $1.0619 * * *$ & $1.0968 * * *$ & $1.0708 * * *$ & $1.0724 * * *$ & $1.0752 * * *$ & $1.1112 * * *$ \\
\hline & $(0.1855)$ & $(0.1592)$ & $(0.1752)$ & $(0.1771)$ & $(0.1585)$ & $(0.1582)$ & $(0.1544)$ & $(0.1536)$ & $(0.1558)$ \\
\hline \multirow[t]{2}{*}{ рор014 } & -0.0915 & 0.3775 & 0.2288 & 0.4097 & $0.5672 * *$ & $0.5783 * *$ & $0.5504 * *$ & $0.7815^{* *}$ & $0.7016 * *$ \\
\hline & $(0.2353)$ & $(0.2822)$ & $(0.3528)$ & (0.3359) & $(0.2738)$ & $(0.2485)$ & $(0.2374)$ & $(0.3459)$ & $(0.2852)$ \\
\hline \multirow[t]{2}{*}{ pop65abv } & $0.2407 *$ & 0.0635 & 0.2561 & 0.0068 & 0.1397 & 0.1381 & 0.1100 & 0.3058 & 0.2248 \\
\hline & $(0.1266)$ & $(0.2660)$ & $(0.2581)$ & $(0.3065)$ & $(0.2941)$ & $(0.3304)$ & $(0.3191)$ & $(0.3454)$ & $(0.3817)$ \\
\hline \multirow[t]{2}{*}{ urban_pop_ptot } & 0.0311 & -0.0579 & -0.0510 & -0.0632 & -0.0888 & -0.1186 & -0.1114 & -0.1349 & -0.1156 \\
\hline & $(0.0612)$ & $(0.0628)$ & $(0.0622)$ & $(0.0768)$ & (0.0729) & $(0.0801)$ & $(0.0752)$ & $(0.0834)$ & $(0.0822)$ \\
\hline \multirow[t]{2}{*}{ lfp_female } & 0.0402 & 0.0774 & 0.0917 & 0.0992 & $0.1155^{*}$ & $0.1136 * *$ & $0.1047 * *$ & $0.1779 *$ & $0.1330^{*}$ \\
\hline & $(0.0521)$ & $(0.0562)$ & $(0.0995)$ & $(0.0656)$ & $(0.0662)$ & $(0.0561)$ & $(0.0531)$ & $(0.0977)$ & $(0.0701)$ \\
\hline \multirow[t]{2}{*}{ hce_pub_texp } & 0.0577 & 0.0567 & 0.0705 & 0.0448 & 0.0502 & 0.0292 & 0.0356 & 0.0509 & 0.0468 \\
\hline & $(0.0354)$ & $(0.0459)$ & $(0.0470)$ & $(0.0500)$ & $(0.0467)$ & $(0.0500)$ & $(0.0463)$ & $(0.0517)$ & $(0.0534)$ \\
\hline \multirow[t]{2}{*}{ hosp_beds_gr } & $0.0365^{*}$ & $0.0450 * * *$ & $0.0382 *$ & $0.0337 *$ & $0.0426 * *$ & $0.0351 *$ & $0.0353 *$ & $0.0396 * *$ & $0.0466 * *$ \\
\hline & $(0.0214)$ & $(0.0169)$ & $(0.0203)$ & $(0.0191)$ & $(0.0211)$ & $(0.0192)$ & $(0.0199)$ & $(0.0198)$ & $(0.0204)$ \\
\hline \multirow[t]{2}{*}{ pollut_pop } & 0.0276 & $0.0428 *$ & $0.0546 * *$ & $0.0491 *$ & $0.0651 * *$ & $0.0562 * *$ & $0.0546 * *$ & $0.0620 * *$ & $0.0740 * *$ \\
\hline & $(0.0225)$ & $(0.0233)$ & $(0.0271)$ & $(0.0277)$ & $(0.0313)$ & $(0.0280)$ & $(0.0256)$ & $(0.0310)$ & $(0.0330)$ \\
\hline \multirow[t]{2}{*}{ trend } & $0.7558 * * *$ & $0.4081 * * *$ & $-0.9660 * * *$ & $0.5042 * * *$ & $0.8316 * * *$ & $0.7903 * * *$ & $0.7832 * * *$ & $0.8358 * * *$ & $0.8370 * * *$ \\
\hline & $(0.2601)$ & $(0.1463)$ & $(0.1924)$ & $(0.1448)$ & $(0.1346)$ & $(0.1285)$ & $(0.1264)$ & $(0.1360)$ & $(0.1341)$ \\
\hline D.diab_nprev & $\begin{array}{c}-0.4893 \\
(0.4127)\end{array}$ & & & & & & & & \\
\hline D.obese_prev & & $\begin{array}{l}-0.4793 \\
(0.7743)\end{array}$ & & & & & & & \\
\hline resid_diab & & & $\begin{array}{c}0.3573 * * \\
(0.1625)\end{array}$ & & & & & & \\
\hline resid_obese & & & & $\begin{array}{c}-0.0030 \\
(0.1190)\end{array}$ & & & & & \\
\hline D.total_kcal & & & & & $\begin{array}{c}0.0098 \\
(0.0114)\end{array}$ & & & & \\
\hline D.total_fat_gcd & & & & & & $\begin{array}{c}0.4234 * * * \\
(0.1304)\end{array}$ & & & \\
\hline D.total_prot_gcd & & & & & & 0.1640 & & & \\
\hline D.anim_prod_fat_gcd & & & & & & & 0.2356 & & \\
\hline & & & & & & & $(0.1988)$ & & \\
\hline D.oils_gcd & & & & & & & $0.1143 * *$ & & \\
\hline & & & & & & & $(0.0542)$ & & \\
\hline D.anim_prod_prot_gcd & & & & & & & $\begin{array}{c}0.3788 \\
(0.2564)\end{array}$ & & \\
\hline cereal_kcal & & & & & & & & $\begin{array}{c}0.0040 \\
(00045)\end{array}$ & \\
\hline fruit_kcal & & & & & & & & 0.0107 & \\
\hline & & & & & & & & $(0.0117)$ & \\
\hline vegs_kcal & & & & & & & & 0.0337 & \\
\hline & & & & & & & & $(0.0351)$ & \\
\hline D.oils_kcal & & & & & & & & 0.0377 *** & \\
\hline & & & & & & & & $(0.0128)$ & \\
\hline D.meat_kcal & & & & & & & & $0.0534 *$ & \\
\hline & & & & & & & & $(0.0285)$ & \\
\hline D.fish_kcal & & & & & & & & 0.0590 & \\
\hline & & & & & & & & $(0.1032)$ & \\
\hline alcohol_kcal & & & & & & & & & $\begin{array}{c}0.0014 \\
(0.0151)\end{array}$ \\
\hline \# Observations & 1038 & 1470 & 1038 & 1470 & 1985 & 1985 & 1979 & 1979 & 1984 \\
\hline \# Countries & 150 & 150 & 150 & 150 & 151 & 151 & 150 & 150 & 150 \\
\hline \# Instruments & 130 & 130 & 130 & 130 & 130 & 131 & 132 & 135 & 130 \\
\hline Hansen-test & 0.237 & 0.549 & 0.153 & 0.377 & 0.236 & 0.231 & 0.256 & 0.307 & 0.299 \\
\hline Diff.-Hansen & 0.246 & 0.538 & 0.164 & 0.352 & 0.230 & 0.191 & 0.232 & 0.263 & 0.251 \\
\hline $\mathrm{AR}(1)$ & 0.000 & 0.000 & 0.001 & 0.000 & 0.000 & 0.000 & 0.000 & 0.000 & 0.000 \\
\hline $\mathrm{AR}(2)$ & 0.318 & 0.164 & 0.467 & 0.242 & 0.324 & 0.349 & 0.334 & 0.334 & 0.289 \\
\hline
\end{tabular}

Notes: See Tables 1-4, Table A.3 in Annex and the respective notes. In regressions (6) and (7) we use sugar in grams per capita per day

for consistency with the unit of measure available for the additional variables for nutrients. 
Figures

Figure 1. World sugar and sweeteners food supply (1961-2011), in millions of tonnes

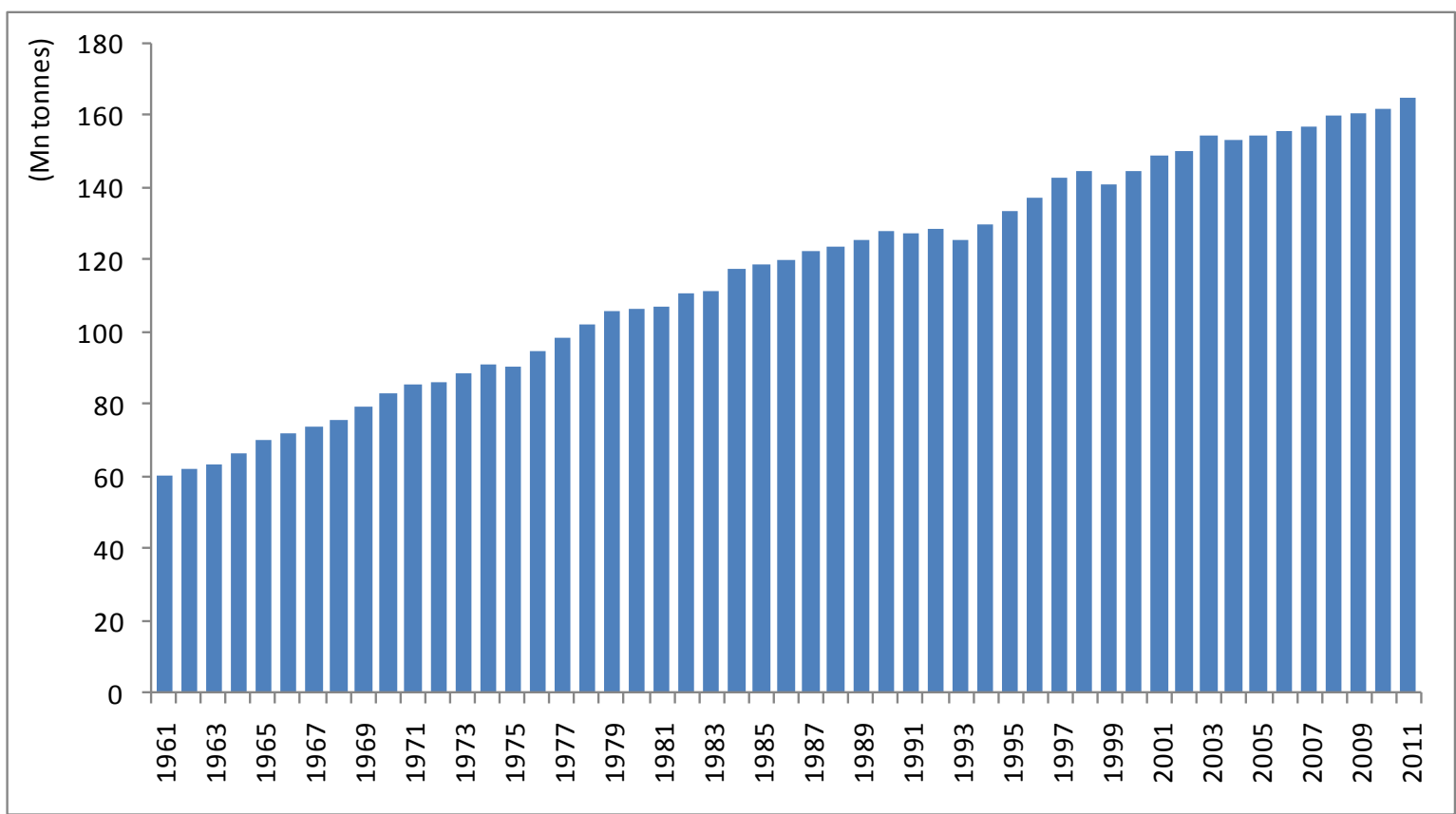

Source: Food and Agriculture Organization of the United Nations (FAOSTAT), Food Supply Database. 
Figure 2. Sugar and sweeteners food supply/availability, diabetes prevalence, diabetes expenditure and total health care expenditure in $\mathbf{2 0 1 0}$

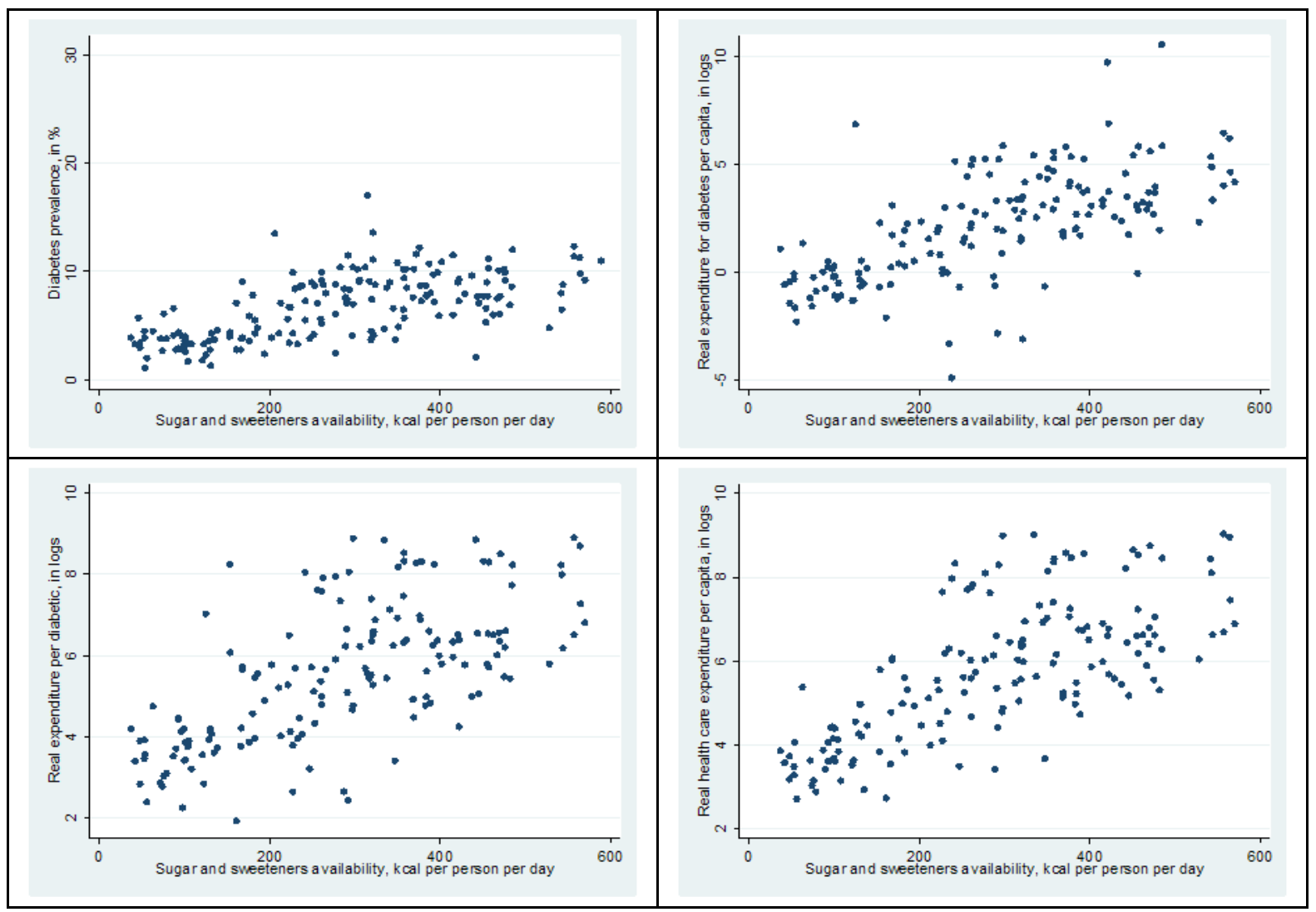

Notes: See Table 1. 
ANNEX

Table A.1. Descriptive Statistics

\begin{tabular}{|c|c|c|c|c|c|}
\hline Variable & Obs. & Mean & Std. Dev. & Min. & Max. \\
\hline rdiab_exp_pc & 1987 & 85.05 & 653.22 & 0.01 & 16524.59 \\
\hline rdiab_exp_ppd & 1987 & 909.00 & 1500.99 & 5.65 & 10666.51 \\
\hline rhcepc & 3067 & 894.82 & 1615.55 & 8.71 & 34663.17 \\
\hline rhcepc_gr & 2897 & 0.40 & 18.81 & -266.05 & 98.54 \\
\hline sugar_swt_kcal & 3047 & 279.21 & 147.23 & 13.00 & 664.00 \\
\hline sugar_ref_kcal & 2996 & 255.14 & 136.21 & 4.00 & 662.00 \\
\hline sugar_swt_gcd & 3045 & 81.11 & 43.33 & 3.26 & 194.43 \\
\hline sugar_ptot_kcal & 3047 & 9.98 & 4.76 & 0.68 & 25.36 \\
\hline sugar_swt_kcal_gr & 3044 & 0.86 & 10.91 & -78.02 & 84.08 \\
\hline rgdppc & 3836 & 11093.09 & 17692.87 & 69.58 & 158603.00 \\
\hline$r g d p p c \_g r$ & 3855 & 2.54 & 6.12 & -62.21 & 141.64 \\
\hline pop014 & 3880 & 30.91 & 10.73 & 11.76 & 50.41 \\
\hline pop65abv & 3880 & 7.28 & 4.93 & 0.70 & 25.71 \\
\hline urban_pop_ptot & 4240 & 56.09 & 24.57 & 7.21 & 100.00 \\
\hline lfp_female & 3720 & 56.25 & 17.37 & 10.40 & 90.50 \\
\hline hce_pub_texp & 3543 & 57.26 & 20.19 & 0.33 & 99.97 \\
\hline hosp_beds & 3014 & 3.43 & 2.96 & 0.10 & 19.57 \\
\hline$h o s p \_b e d s \_g r$ & 3001 & -1.54 & 12.21 & -184.58 & 241.29 \\
\hline pollut_pop & 3512 & 73.11 & 37.39 & 0.00 & 100.00 \\
\hline diab_nprev & 2504 & 7.29 & 4.13 & 0.80 & 37.90 \\
\hline obese_prev & 2851 & 16.13 & 12.32 & 0.05 & 81.01 \\
\hline total_kcal & 3047 & 2713.96 & 477.10 & 1571.00 & 3833.00 \\
\hline total_fat_gcd & 3047 & 80.09 & 34.95 & 13.41 & 175.46 \\
\hline total_prot_gcd & 3047 & 76.26 & 20.47 & 33.64 & 138.05 \\
\hline anim_prod_fat_gcd & 3047 & 36.42 & 25.05 & 2.26 & 110.97 \\
\hline oils_gcd & 3011 & 57.62 & 66.02 & 0.00 & 515.54 \\
\hline anim_prod_prot_gcd & 3047 & 34.13 & 20.26 & 3.68 & 101.17 \\
\hline cereal_kcal & 3047 & 1097.82 & 327.32 & 219.00 & 2231.00 \\
\hline fruit_kcal & 3047 & 102.86 & 73.84 & 4.00 & 522.00 \\
\hline vegs_kcal & 3047 & 55.65 & 37.53 & 4.00 & 234.00 \\
\hline oils_kcal & 3013 & 317.99 & 152.37 & 23.00 & 849.00 \\
\hline meat_kcal & 3047 & 217.32 & 149.18 & 11.00 & 764.00 \\
\hline fish_kcal & 3045 & 35.91 & 38.52 & 0.00 & 385.00 \\
\hline alcohol_kcal & 3030 & 76.88 & 71.90 & 0.00 & 474.00 \\
\hline unemp_rate & 3480 & 8.86 & 6.27 & 0.10 & 39.30 \\
\hline surv65_fem & 3686 & 74.32 & 16.19 & 14.90 & 94.72 \\
\hline surv65_male & 3686 & 65.16 & 15.22 & 16.88 & 90.24 \\
\hline life_exp_fem & 3798 & 70.80 & 10.47 & 35.35 & 86.70 \\
\hline life_exp_male & 3798 & 66.00 & 9.27 & 28.10 & 81.80 \\
\hline pop_dens & 4247 & 376.70 & 1821.73 & 0.14 & 21595.30 \\
\hline lfp_ratio_fm & 3720 & 68.43 & 20.00 & 13.68 & 108.09 \\
\hline hce_pub_gdp & 3543 & 3.67 & 2.35 & 0.01 & 21.57 \\
\hline physicians & 3052 & 1.57 & 1.43 & 0.01 & 7.74 \\
\hline pollut_expos & 3547 & 17.85 & 10.44 & 1.14 & 75.06 \\
\hline
\end{tabular}

Notes: See Table 1. Time-period: 1995-2014. 156 countries in the sample (OECD countries in Italic): Afghanistan, Albania, Algeria, Angola, Antigua and Barbuda, Argentina, Armenia, Australia, Austria, Bahamas, Bangladesh, Barbados, Belgium, Belize, Benin, Bolivia, Bosnia and Herzegovina, Botswana, Brazil, Brunei Darussalam, Bulgaria, Burkina Faso, Cape Verde, Cambodia, Cameroon, Canada, Central African Republic, Chad, Chile, China, Colombia, Rep. Congo, Costa Rica, Cote d'Ivoire, Croatia, Cyprus, Czech Rep., Denmark, Djibouti, Dominican Republic, Ecuador, Egypt, Arab Rep., El Salvador, Estonia, Ethiopia, Fiji, Finland, France, Gabon, Gambia, Georgia, Germany, Ghana, Greece, Grenada, Guatemala, Guinea, Guinea-Bissau, Guyana, Haiti, Honduras, Hungary, Iceland, India, Indonesia, Iran, Islamic Rep., Iraq, Ireland, Israel, Italy, Jamaica, Japan, Jordan, Kazakhstan, Kenya, Rep. Korea, Kuwait, Kyrgyz Rep., Lao PDR, Latvia, Lebanon, Lesotho, Liberia, Lithuania, Luxembourg, Macedonia, Madagascar, Malawi, Malaysia, Maldives, Mali, Malta, Mauritania, Mauritius, Mexico, Moldova, Mongolia, Montenegro, Morocco, Mozambique, Myanmar, Namibia, Nepal, Netherlands, New Zealand, Nicaragua, Niger, Nigeria, Norway, Oman, Pakistan, Panama, Paraguay, Peru, Philippines, Poland, Portugal, Romania, Russian Federation, Rwanda, Samoa, Sao Tome and Principe, Saudi Arabia, Senegal, Serbia, Sierra Leone, Slovak Rep., Slovenia, Solomon Islands, South Africa, Spain, Sri Lanka, St. Lucia, St. Vincent and the Grenadines, Sudan, Suriname, Swaziland, Sweden, Switzerland, Tanzania, Thailand, Timor-Leste, Togo, Trinidad and Tobago, Tunisia, Turkey, Uganda, Ukraine, United Arab Emirates, United Kingdom, United States, Uruguay, Vanuatu, Venezuela, Vietnam, and Zambia. 
Table A.2. Panel unit root tests

\begin{tabular}{|c|c|c|c|c|c|}
\hline \multirow[b]{2}{*}{ Variable } & \multirow{2}{*}{$\frac{\text { IPS test }}{W t \text {-bar }}$} & \multicolumn{4}{|c|}{ ADF Fisher-type tests } \\
\hline & & $P$ & $Z$ & $L^{*}$ & $P m$ \\
\hline$r d i a b \_e x p \_p c$ & $-11.44(0.000)$ & $556.54(0.000)$ & $-6.28(0.000)$ & $-5.87(0.000)$ & $8.30(0.000)$ \\
\hline lnrdiab_exp_pc & $-5.94(0.000)$ & $637.58(0.000)$ & $-10.85(0.000)$ & $-10.54(0.000)$ & $11.41(0.000)$ \\
\hline rdiab_exp_ppd & $-6.66(0.000)$ & $672.97(0.000)$ & $-10.77(0.000)$ & $-10.27(0.000)$ & $12.77(0.000)$ \\
\hline lnrdiab_exp_ppd & $-3.77(0.000)$ & $718.69(0.000)$ & $-13.15(0.000)$ & $-12.72(0.000)$ & $14.52(0.000)$ \\
\hline rhcepc & $-0.27(0.391)$ & $490.39(0.000)$ & $2.05(0.980)$ & $0.23(0.592)$ & $5.67(0.000)$ \\
\hline lnrhcepc & $1.64(0.949)$ & $334.43(0.605)$ & $2.43(0.993)$ & $2.08(0.981)$ & $-0.29(614)$ \\
\hline$r h c e p c \_g r$ & $-17.08(0.000)$ & $1090.4(0.000)$ & $-18.98(0.000)$ & $-21.49(0.000)$ & $28.61(0.000)$ \\
\hline sugar_swt_kcal & $-5.81(0.000)$ & $542.43(0.000)$ & $-4.27(0.000)$ & $-5.30(0.000)$ & $7.18(0.000)$ \\
\hline lnsugar_swt_kcal & $-10.62(0.000)$ & $662.02(0.000)$ & $-7.96(0.000)$ & $-9.27(0.000)$ & $11.68(0.000)$ \\
\hline sugar_ref_kcal & $-3.44(0.000)$ & $465.68(0.000)$ & $-3.61(0.000)$ & $-3.80(0.000)$ & $4.55(0.000)$ \\
\hline sugar_swt_gcd & $-10.99(0.000)$ & $545.94(0.000)$ & $-4.66(0.000)$ & $-5.49(0.000)$ & $7.31(0.000)$ \\
\hline sugar_ptot_kcal & $-6.69(0.000)$ & $608.85(0.000)$ & $-6.11(0.000)$ & $-7.45(0.000)$ & $9.68(0.000)$ \\
\hline sugar_swt_kcal_gr & $-56.73(0.000)$ & $4572.9(0.000)$ & $-57.91(0.000)$ & $-95.58(0.000)$ & $159.08(0.000)$ \\
\hline rgdppc & $16.65(1.000)$ & $231.26(1.000)$ & $11.92(1.000)$ & $12.76(1.000)$ & $-5.79(1.000)$ \\
\hline $\ln r g d p p c$ & $3.16(0.999)$ & $491.99(0.001)$ & $1.88(0.970)$ & $0.86(0.805)$ & $3.49(0.000)$ \\
\hline$r g d p p c \_g r$ & $-37.26(0.000)$ & $2763.7(0.000)$ & $-39.00(0.000)$ & $-52.79(0.000)$ & $82.47(0.000)$ \\
\hline pop014 & $-11.75(0.000)$ & $1329.5(0.000)$ & $-14.50(0.000)$ & $-20.27(0.000)$ & $33.80(0.000)$ \\
\hline pop65abv & $-2.57(0.005)$ & $928.11(0.000)$ & $-8.93(0.000)$ & $-11.50(0.000)$ & $19.38(0.000)$ \\
\hline urban_pop_ptot & $-12.30(0.000)$ & $1080.8(0.000)$ & $-12.80(0.000)$ & $-15.34(0.000)$ & $22.55(0.000)$ \\
\hline lfp_female & $-2.31(0.010)$ & $583.39(0.000)$ & $-1.86(0.032)$ & $-3.38(0.000)$ & $7.50(0.000)$ \\
\hline hce_pub_texp & $-1.70(0.045)$ & $480.70(0.000)$ & $-1.74(0.041)$ & $-2.16(0.016)$ & $3.81(0.000)$ \\
\hline hosp_beds & $7.53(1.000)$ & 305.14 (0.999) & $6.73(1.000)$ & $6.98(1.000)$ & $-2.78(0.997)$ \\
\hline$h o s p \_b e d s \_g r$ & $-22.87(0.000)$ & $1920.2(0.000)$ & $-27.23(0.000)$ & $-37.24(0.000)$ & $55.87(0.000)$ \\
\hline pollut_pop & $-3.89(0.000)$ & $496.86(0.000)$ & $-4.11(0.000)$ & $-4.08(0.000)$ & $4.85(0.000)$ \\
\hline D.diab_nprev & $-7.58(0.000)$ & $1082.1(0.000)$ & $-12.18(0.000)$ & $-16.63(0.000)$ & $22.24(0.000)$ \\
\hline D.obese_prev & $-12.63(0.000)$ & $1118.8(0.000)$ & $-17.17(0.000)$ & $-23.69(0.000)$ & $28.36(0.000)$ \\
\hline D.total_kcal & $-49.84(0.000)$ & $3802.7(0.000)$ & $-51.69(0.000)$ & $-79.35(0.000)$ & $130.05(0.000)$ \\
\hline D.total_fat_gcd & $-53.91(0.000)$ & $4236.3(0.000)$ & $-55.42(0.000)$ & $-88.43(0.000)$ & $146.49(0.000)$ \\
\hline D.total_prot_gcd & $-51.60(0.000)$ & $3984.3(0.000)$ & $-53.39(0.000)$ & $-83.10(0.000)$ & $136.90(0.000)$ \\
\hline D.anim_prod_fat_gcd & $-47.23(0.000)$ & $3516.6(0.000)$ & $-49.30(0.000)$ & $-73.33(0.000)$ & $119.27(0.000)$ \\
\hline D.oils_gcd & $-60.66(0.000)$ & $4976.3(0.000)$ & $-61.52(0.000)$ & $-104.61(0.000)$ & $175.44(0.000)$ \\
\hline D.anim_prod_prot_gcd & $-40.02(0.000)$ & $3637.9(0.000)$ & $-49.87(0.000)$ & $-75.84(0.000)$ & $123.84(0.000)$ \\
\hline cereal_kcal & $-3.59(0.000)$ & $535.94(0.000)$ & $-3.65(0.000)$ & $-4.69(0.000)$ & $6.93(0.000)$ \\
\hline fruit_kcal & $-5.69(0.000)$ & $651.90(0.000)$ & $-7.04(0.000)$ & $-7.94(0.000)$ & $8.87(0.000)$ \\
\hline vegs_kcal & $-7.47(0.000)$ & $764.99(0.000)$ & $-8.17(0.000)$ & $-9.36(0.000)$ & $11.32(0.000)$ \\
\hline D.oils_kcal & $-59.07(0.000)$ & $4778.5(0.000)$ & $-60.08(0.000)$ & $-100.40(0.000)$ & $167.94(0.000)$ \\
\hline D.meat_kcal & $-49.49(0.000)$ & $3742.8(0.000)$ & $-51.45(0.000)$ & $-78.13(0.000)$ & $127.80(0.000)$ \\
\hline D.fish_kcal & $-54.73(0.000)$ & $4665.0(0.000)$ & $-58.83(0.000)$ & $-98.00(0.000)$ & $162.55(0.000)$ \\
\hline alcohol_kcal & $-1.73(0.042)$ & $502.41(0.000)$ & $-2.72(0.003)$ & $-3.29(0.001)$ & $5.76(0.000)$ \\
\hline unemp_rate & $-5.49(0.000)$ & $614.92(0.000)$ & $-7.69(0.000)$ & $-8.35(0.000)$ & $10.12(0.000)$ \\
\hline surv65_fem & $-3.27(0.001)$ & $628.46(0.000)$ & $-3.72(0.000)$ & $-4.49(0.000)$ & $8.63(0.000)$ \\
\hline surv65_male & $-9.30(0.000)$ & $696.69(0.000)$ & $-9.76(0.000)$ & $-10.07(0.000)$ & $11.08(0.000)$ \\
\hline life_exp_fem & $-4.43(0.000)$ & $1389.2(0.000)$ & $-5.20(0.000)$ & $-14.95(0.000)$ & $34.81(0.000)$ \\
\hline life_exp_male & $-3.21(0.001)$ & $1288.1(0.000)$ & $-4.56(0.000)$ & $-11.29(0.000)$ & $31.24(0.000)$ \\
\hline pop_dens & $-13.98(0.000)$ & $2052.0(0.000)$ & $-17.40(0.000)$ & $-31.80(0.000)$ & $55.70(0.000)$ \\
\hline lfp_ratio_fm & $-2.71(0.003)$ & $536.31(0.000)$ & $-2.79(0.003)$ & $-3.58(0.000)$ & $6.02(0.000)$ \\
\hline$h c e \_p u b \_g d p$ & $-3.17(0.001)$ & $578.77(0.000)$ & $-3.42(0.000)$ & $-4.58(0.000)$ & $7.39(0.000)$ \\
\hline physicians & $-2.75(0.003)$ & $557.16(0.000)$ & $-3.03(0.001)$ & $-3.38(0.000)$ & $5.47(0.000)$ \\
\hline pollut_expos & $-4.85(0.000)$ & $552.45(0.000)$ & $-5.47(0.000)$ & $-5.66(0.000)$ & $6.89(0.000)$ \\
\hline
\end{tabular}

Notes: See Tables D1 and D2. IPS stands for the Im-Pesaran-Shin panel unit root test; the $W t$-bar statistic is reported followed by the respective $p$-value in parentheses. Four Fisher-type ADF unit-root test statistics are also reported (the respective $p$-values are in parentheses): inverse chi-squared $P$; inverse normal $Z$; inverse logit $L^{*}$; and the modified inverse chi-squared $P m$. One lag of the series is used in the ADF regressions, but different lag structures produce similar results. Phillips-Perron unit-root tests were also considered, but the conclusions remain unchanged (those results are not reported here but are available upon request). These tests are preferred due to the fact of the panel is not strongly balanced. " $D$." stands for the first-difference of the respective variable. 
Table A.3. Sensitivity analysis: diabetes expenditure

\begin{tabular}{|c|c|c|c|c|c|c|}
\hline \multirow[t]{2}{*}{ Dep. Variable: } & \multicolumn{3}{|c|}{ lnrdiab_exp_pc } & \multicolumn{3}{|c|}{ lnrdiab_exp_ppd } \\
\hline & (1) & $(2)$ & (3) & (4) & $(5)$ & (6) \\
\hline L.lnrdiab_exp_pc & $\begin{array}{c}0.4751 * * * \\
(0.1484)\end{array}$ & $\begin{array}{c}0.4811 * * * \\
(0.1590)\end{array}$ & $\begin{array}{c}0.4785 * * * \\
(0.1667)\end{array}$ & & & \\
\hline L.lnrdiab_exp_ppd & & & & $\begin{array}{c}0.7991 * * * \\
(0.1103)\end{array}$ & $\begin{array}{c}0.8094 * * * \\
(0.1110)\end{array}$ & $\begin{array}{c}0.8019 * * * \\
(0.1031)\end{array}$ \\
\hline lnsugar_swt_kcal & $\begin{array}{l}1.9507 * * \\
(0.7583)\end{array}$ & $\begin{array}{c}2.9909 * * \\
(1.2268)\end{array}$ & $\begin{array}{c}3.3141 * * \\
(1.3501)\end{array}$ & $\begin{array}{c}0.5778 * * \\
(0.2351)\end{array}$ & $\begin{array}{c}0.7685 * * \\
(0.3714)\end{array}$ & $\begin{array}{c}0.9585^{* *} * \\
(0.4147)\end{array}$ \\
\hline$r g d p p c \_g r$ & $\begin{array}{c}0.0150 * * \\
(0.0064)\end{array}$ & $\begin{array}{c}0.0141 * * \\
(0.0071)\end{array}$ & $\begin{array}{l}0.0138^{*} \\
(0.0079)\end{array}$ & $\begin{array}{l}-0.0001 \\
(0.0041)\end{array}$ & $\begin{array}{c}0.0013 \\
(0.0045)\end{array}$ & $\begin{array}{c}0.0003 \\
(0.0043)\end{array}$ \\
\hline рор014 & $\begin{array}{c}0.0337 \\
(0.0478)\end{array}$ & $\begin{array}{c}0.0965 \\
(0.0699)\end{array}$ & $\begin{array}{c}0.0961 \\
(0.0759)\end{array}$ & $\begin{array}{c}0.0166 \\
(0.0140)\end{array}$ & $\begin{array}{c}0.0226 \\
(0.0205)\end{array}$ & $\begin{array}{l}0.0390 * \\
(0.0215)\end{array}$ \\
\hline pop65abv & $\begin{array}{c}0.0841 * * \\
(0.0394)\end{array}$ & $\begin{array}{c}0.1268 * * \\
(0.0563)\end{array}$ & $\begin{array}{c}0.1128 \\
(0.0702)\end{array}$ & $\begin{array}{c}0.0383 * * * \\
(0.0146)\end{array}$ & $\begin{array}{l}0.0396 * \\
(0.0225)\end{array}$ & $\begin{array}{c}0.0525^{* *} \\
(0.0245)\end{array}$ \\
\hline D.obese_prev & $\begin{array}{c}0.1591 \\
(0.1452)\end{array}$ & & & $\begin{array}{c}0.0530 \\
(0.0445)\end{array}$ & & \\
\hline resid_diab & & $\begin{array}{c}0.0831 * * \\
(0.0411)\end{array}$ & & & $\begin{array}{c}0.0390 \\
(0.0250)\end{array}$ & \\
\hline resid_obese & & & $\begin{array}{c}-0.0327 \\
(0.0419)\end{array}$ & & & $\begin{array}{c}0.0068 \\
(0.0194)\end{array}$ \\
\hline trend & $\begin{array}{c}0.0587 * * * \\
(0.0130)\end{array}$ & $\begin{array}{c}0.0664 * * \\
(0.0272)\end{array}$ & $\begin{array}{c}0.1006 * * * \\
(0.0336)\end{array}$ & $\begin{array}{c}0.0438 * * * \\
(0.0069)\end{array}$ & $\begin{array}{c}0.0560 * * * \\
(0.0091)\end{array}$ & $\begin{array}{c}0.0500 * * * \\
(0.0121)\end{array}$ \\
\hline \# Observations & 1255 & 1255 & 1255 & 1255 & 1255 & 1255 \\
\hline \# Countries & 154 & 155 & 155 & 154 & 155 & 155 \\
\hline \# Instruments & 130 & 130 & 130 & 130 & 130 & 130 \\
\hline Hansen test & 0.6915 & 0.1025 & 0.8027 & 0.6820 & 0.0894 & 0.6947 \\
\hline Diff.-Hansen & & 0.0751 & 0.7483 & & 0.0639 & 0.6181 \\
\hline $\operatorname{AR}(1)$ & 0.0318 & 0.0338 & 0.0316 & 0.0087 & 0.0080 & 0.0085 \\
\hline $\operatorname{AR}(2)$ & 0.6802 & 0.7310 & 0.9261 & 0.4822 & 0.5207 & 0.5328 \\
\hline
\end{tabular}

Notes: See Table 2. The variables resid_diab and resid_obese are the residuals of the estimation of, respectively, diabetes prevalence and obesity prevalence on sugar intake. Hence, these represent the part of diabetes prevalence and obesity prevalence that is not explained by sugar intake. 
Table A.4. Sensitivity analysis: total health care expenditure

\begin{tabular}{|c|c|c|c|c|c|c|c|c|c|}
\hline & (1) & (2) & (3) & (4) & (5) & (6) & (7) & (8) & (9) \\
\hline L.rhcepc_gr & $\begin{array}{c}0.2145^{* * * *} \\
(0.0403)\end{array}$ & $\begin{array}{c}0.1653 * * * \\
(0.0508)\end{array}$ & $\begin{array}{c}0.1654 * * * \\
(0.0511)\end{array}$ & $\begin{array}{c}0.1669 * * * \\
(0.0530)\end{array}$ & $\begin{array}{c}0.1660 * * * \\
(0.0529)\end{array}$ & $\begin{array}{c}0.1660 * * * \\
(0.0523)\end{array}$ & $\begin{array}{c}0.1824 * * * * \\
(0.0522)\end{array}$ & $\begin{array}{c}0.1631 \text { *** } \\
(0.0532)\end{array}$ & $\begin{array}{c}0.1374 * * * \\
(0.0530)\end{array}$ \\
\hline sugar_swt_kcal & $\begin{array}{c}0.1246 * * * \\
(0.0425)\end{array}$ & $\begin{array}{c}0.1015 \text { **** } \\
(0.0346)\end{array}$ & $\begin{array}{c}0.0994 * * * \\
(0.0340)\end{array}$ & $\begin{array}{c}0.0878 * * \\
(0.0346)\end{array}$ & $\begin{array}{c}0.0846 * * * \\
(0.0322)\end{array}$ & $\begin{array}{c}0.0862 * * * * \\
(0.0295)\end{array}$ & $\begin{array}{c}0.0634 * * \\
(0.0303)\end{array}$ & $\begin{array}{c}0.1044 * * * \\
(0.0380)\end{array}$ & $\begin{array}{c}0.0424 * * \\
(0.0210)\end{array}$ \\
\hline$r g d p p c \_g r$ & & $\begin{array}{c}1.1312 * * * \\
(0.1585)\end{array}$ & $\begin{array}{c}1.1274 * * * \\
(0.1571)\end{array}$ & $\begin{array}{c}1.1032 * * * \\
(0.1562)\end{array}$ & $\begin{array}{c}1.1105^{* * * *} \\
(0.1565)\end{array}$ & $\begin{array}{c}1.1377 * * * \\
(0.1618)\end{array}$ & $\begin{array}{c}1.2417 * * * \\
(0.1567)\end{array}$ & $\begin{array}{c}1.1074 * * * \\
(0.1571)\end{array}$ & $\begin{array}{c}0.9517 * * * \\
(0.1668)\end{array}$ \\
\hline рор014 & $\begin{array}{c}0.5609 \\
(0.4328)\end{array}$ & & & $\begin{array}{c}0.7830^{* * *} \\
(0.3146)\end{array}$ & $\begin{array}{c}0.6643 * * \\
(0.2683)\end{array}$ & $\begin{array}{c}0.6219 * * \\
(0.2815)\end{array}$ & $\begin{array}{l}0.4476^{*} \\
(0.2605)\end{array}$ & $\begin{array}{c}0.7850 * * \\
(0.3054)\end{array}$ & $\begin{array}{l}0.3872^{*} \\
(0.2237)\end{array}$ \\
\hline pop65abv & $\begin{array}{c}-0.0625 \\
(0.7484)\end{array}$ & & & $\begin{array}{c}0.0680 \\
(0.3765)\end{array}$ & $\begin{array}{c}0.1164 \\
(0.3426)\end{array}$ & $\begin{array}{l}-0.1530 \\
(0.4657)\end{array}$ & $\begin{array}{c}0.1670 \\
(0.3175)\end{array}$ & $\begin{array}{c}0.3724 \\
(0.3790)\end{array}$ & $\begin{array}{c}0.1220 \\
(0.2346)\end{array}$ \\
\hline urban_pop_ptot & $\begin{array}{c}-0.3272 * * \\
(0.1343)\end{array}$ & $\begin{array}{c}-0.1721 * \\
(0.0945)\end{array}$ & $\begin{array}{c}-0.1437 \\
(0.0878)\end{array}$ & & $\begin{array}{l}-0.1138 \\
(0.0787)\end{array}$ & $\begin{array}{l}-0.1353^{*} \\
(0.0778)\end{array}$ & $\begin{array}{l}-0.1076 \\
(0.0863)\end{array}$ & $\begin{array}{l}-0.1501 \\
(0.0922)\end{array}$ & $\begin{array}{c}-0.0536 \\
(0.0577)\end{array}$ \\
\hline lfp_female & $\begin{array}{c}0.1304 \\
(0.1540)\end{array}$ & $\begin{array}{c}0.0803 \\
(0.0612)\end{array}$ & $\begin{array}{l}0.1025^{*} \\
(0.0619)\end{array}$ & $\begin{array}{c}0.1844 * * \\
(0.0893)\end{array}$ & & $\begin{array}{c}0.1452 * * \\
(0.0663)\end{array}$ & $\begin{array}{c}0.0896 \\
(0.0590)\end{array}$ & $\begin{array}{c}0.2223^{* *} \\
(0.0976)\end{array}$ & $\begin{array}{c}0.0530 \\
(0.0529)\end{array}$ \\
\hline hce_pub_texp & $\begin{array}{c}0.0258 \\
(0.0800)\end{array}$ & $\begin{array}{c}0.0040 \\
(0.0643)\end{array}$ & $\begin{array}{c}0.0089 \\
(0.0619)\end{array}$ & $\begin{array}{c}0.0218 \\
(0.0594)\end{array}$ & $\begin{array}{c}0.0470 \\
(0.0513)\end{array}$ & & $\begin{array}{c}0.0754 \\
(0.0473)\end{array}$ & $\begin{array}{c}0.0212 \\
(0.0589)\end{array}$ & $\begin{array}{c}0.0622 \\
(0.0388)\end{array}$ \\
\hline hosp_beds_gr & $\begin{array}{c}0.0299 \\
(0.0190)\end{array}$ & $\begin{array}{c}0.0481 * * \\
(0.0190)\end{array}$ & $\begin{array}{c}0.0474 * * \\
(0.0191)\end{array}$ & $\begin{array}{c}0.0440 * * \\
(0.0193)\end{array}$ & $\begin{array}{c}0.0452 * * \\
(0.0196)\end{array}$ & $\begin{array}{c}0.0440 * * \\
(0.0202)\end{array}$ & & $\begin{array}{l}0.0451^{*} \\
(0.0232)\end{array}$ & $\begin{array}{c}0.0353 \\
(0.0237)\end{array}$ \\
\hline pollut_pop & $\begin{array}{l}0.1011^{*} \\
(0.0565)\end{array}$ & $\begin{array}{l}0.0561 * \\
(0.0291)\end{array}$ & $\begin{array}{l}0.0484^{*} \\
(0.0269)\end{array}$ & $\begin{array}{c}0.0879 * * \\
(0.0378)\end{array}$ & $\begin{array}{c}0.0751 * * \\
(0.0327)\end{array}$ & $\begin{array}{c}0.0845^{* * * *} \\
(0.0308)\end{array}$ & $\begin{array}{l}0.0579 * \\
(0.0322)\end{array}$ & & $\begin{array}{c}0.0506^{* * *} \\
(0.0243)\end{array}$ \\
\hline trend & $\begin{array}{c}0.7487 * * * \\
(0.1767)\end{array}$ & $\begin{array}{c}0.7508^{* * * *} \\
(0.1282)\end{array}$ & $\begin{array}{c}0.7643^{* * * *} \\
(0.1278)\end{array}$ & $\begin{array}{c}0.8273 * * * \\
(0.1371)\end{array}$ & $\begin{array}{c}0.8156^{* * * *} \\
(0.1291)\end{array}$ & $\begin{array}{c}0.7823 * * * * \\
(0.1479)\end{array}$ & $\begin{array}{c}0.8625 * * * \\
(0.1546)\end{array}$ & $\begin{array}{c}0.8510^{* * * *} \\
(0.1418)\end{array}$ & \\
\hline unemp_rate & $\begin{array}{c}-1.1661^{*} \\
(0.6466)\end{array}$ & & & & & & & & \\
\hline surv65 fem & & $\begin{array}{c}-0.7499 * * * * \\
(0.2471)\end{array}$ & & & & & & & \\
\hline surv65_male & & $\begin{array}{c}0.3808 * * \\
(0.1825)\end{array}$ & & & & & & & \\
\hline life_exp_fem & & & $\begin{array}{c}-1.5234 * * * \\
(0.5665)\end{array}$ & & & & & & \\
\hline life_exp_male & & & $\begin{array}{l}0.9905^{*} \\
(0.5074)\end{array}$ & & & & & & \\
\hline pop_dens & & & & $\begin{array}{l}-0.0029 \\
(0.0051)\end{array}$ & & & & & \\
\hline lfp_ratio_fm & & & & & $\begin{array}{c}0.1377 * * \\
(0.0686)\end{array}$ & & & & \\
\hline$h c e \_p u b \_g d p$ & & & & & & $\begin{array}{c}1.1033 \\
(0.7253)\end{array}$ & & & \\
\hline physicians & & & & & & & $\begin{array}{c}-0.4458 \\
(0.8972)\end{array}$ & & \\
\hline pollut_expos & & & & & & & & $\begin{array}{c}0.4123 * * \\
(0.1819)\end{array}$ & \\
\hline \# Observations & 1922 & 1987 & 1987 & 1984 & 1987 & 1987 & 1980 & 1987 & 1987 \\
\hline \# Countries & 145 & 151 & 151 & 151 & 151 & 151 & 151 & 151 & 151 \\
\hline \# Instruments & 99 & 129 & 129 & 129 & 129 & 129 & 132 & 129 & 143 \\
\hline Hansen-test & 0.121 & 0.381 & 0.387 & 0.287 & 0.312 & 0.319 & 0.287 & 0.349 & 0.344 \\
\hline Diff.-Hansen & 0.084 & 0.332 & 0.341 & 0.267 & 0.278 & 0.295 & 0.288 & 0.305 & 0.291 \\
\hline $\mathrm{AR}(1)$ & 0.000 & 0.000 & 0.000 & 0.000 & 0.000 & 0.000 & 0.000 & 0.000 & 0.000 \\
\hline $\operatorname{AR}(2)$ & 0.276 & 0.284 & 0.282 & 0.302 & 0.290 & 0.277 & 0.308 & 0.281 & 0.277 \\
\hline
\end{tabular}

Notes: See Tables 1, 4 and 5, and the respective notes. In regression (9) the trend is replaced by time dummies. 
Table A.5. Robustness checks: lags of sugar and estimators

\begin{tabular}{|c|c|c|c|c|c|c|c|}
\hline & \multicolumn{5}{|c|}{ Lags of the sugar variable } & \multicolumn{2}{|c|}{ Alternative estimators } \\
\hline & $\begin{array}{c}\text { Lag } 1 \\
(1)\end{array}$ & $\begin{array}{c}\text { Lag } 2 \\
(2)\end{array}$ & $\begin{array}{c}\text { Lag3 } \\
\text { (3) }\end{array}$ & $\begin{array}{c}\text { Lag } 4 \\
(4)\end{array}$ & $\begin{array}{c}\text { Lag } 5 \\
(5)\end{array}$ & $\begin{array}{c}\text { Diff.GMM } \\
(6)\end{array}$ & $\begin{array}{l}\mathrm{FE} \\
(7)\end{array}$ \\
\hline L.rhcepc_gr & $\begin{array}{c}0.1685 * * * \\
(0.0539)\end{array}$ & $\begin{array}{c}0.1683 * * * \\
(0.0530)\end{array}$ & $\begin{array}{c}0.1706 * * * \\
(0.0529)\end{array}$ & $\begin{array}{c}0.1702 * * * \\
(0.0530)\end{array}$ & $\begin{array}{c}0.1757 * * * \\
(0.0532)\end{array}$ & $\begin{array}{c}0.1586 * * * \\
(0.0511)\end{array}$ & $\begin{array}{c}0.1186 * * * \\
(0.0408)\end{array}$ \\
\hline L.sugar_swt_kcal & $\begin{array}{c}0.0685^{* * *} \\
(0.0343)\end{array}$ & & & & & & \\
\hline L2.sugar_swt_kcal & & $\begin{array}{l}0.0505^{*} \\
(0.0281)\end{array}$ & & & & & \\
\hline L3.sugar_swt_kcal & & & $\begin{array}{c}0.0281 \\
(0.0243)\end{array}$ & & & & \\
\hline L4.sugar_swt_kcal & & & & $\begin{array}{c}0.0483 * * \\
(0.0247)\end{array}$ & & & \\
\hline L5.sugar_swt_kcal & & & & & $\begin{array}{l}-0.0176 \\
(0.0234)\end{array}$ & & \\
\hline sugar_swt_kcal & & & & & & $\begin{array}{c}0.1547 * * * \\
(0.0413)\end{array}$ & $\begin{array}{c}0.0356^{* *} \\
(0.0140)\end{array}$ \\
\hline$r g d p p c \_g r$ & $\begin{array}{c}1.1476 * * * \\
(0.1511)\end{array}$ & $\begin{array}{c}1.1622 * * * \\
(0.1458)\end{array}$ & $\begin{array}{c}1.1577 * * * \\
(0.1472)\end{array}$ & $\begin{array}{c}1.1639 * * * \\
(0.1496)\end{array}$ & $\begin{array}{c}1.1161 * * * \\
(0.1504)\end{array}$ & $\begin{array}{c}1.3038 * * * \\
(0.2052)\end{array}$ & $\begin{array}{c}1.5932 * * * \\
(0.3122)\end{array}$ \\
\hline рор014 & $\begin{array}{c}0.5534 * * \\
(0.2796)\end{array}$ & $\begin{array}{l}0.4292 * \\
(0.2338)\end{array}$ & $\begin{array}{c}0.2598 \\
(0.1850)\end{array}$ & $\begin{array}{l}0.3831 * \\
(0.2043)\end{array}$ & $\begin{array}{l}-0.0596 \\
(0.1700)\end{array}$ & $\begin{array}{l}-0.2765 \\
(0.6778)\end{array}$ & $\begin{array}{c}0.1024 \\
(0.3174)\end{array}$ \\
\hline pop65abv & $\begin{array}{c}0.1007 \\
(0.2753)\end{array}$ & $\begin{array}{c}0.0832 \\
(0.2436)\end{array}$ & $\begin{array}{c}0.0587 \\
(0.1621)\end{array}$ & $\begin{array}{c}0.0370 \\
(0.2669)\end{array}$ & $\begin{array}{c}0.0411 \\
(0.1143)\end{array}$ & $\begin{array}{c}0.9262 * * \\
(0.4658)\end{array}$ & $\begin{array}{c}0.9231 \\
(0.8487)\end{array}$ \\
\hline urban_pop_ptot & $\begin{array}{l}-0.1013 \\
(0.0819)\end{array}$ & $\begin{array}{l}-0.0686 \\
(0.0671)\end{array}$ & $\begin{array}{l}-0.0298 \\
(0.0541)\end{array}$ & $\begin{array}{l}-0.0730 \\
(0.0639)\end{array}$ & $\begin{array}{c}0.0526 \\
(0.0444)\end{array}$ & $\begin{array}{c}0.0026 \\
(0.4326)\end{array}$ & $\begin{array}{c}0.2837 \\
(0.2542)\end{array}$ \\
\hline lfp_female & $\begin{array}{l}0.1337 * \\
(0.0774)\end{array}$ & $\begin{array}{c}0.0859 \\
(0.0577)\end{array}$ & $\begin{array}{c}0.0524 \\
(0.0476)\end{array}$ & $\begin{array}{l}0.0898^{*} \\
(0.0514)\end{array}$ & $\begin{array}{c}-0.0246 \\
(0.0467)\end{array}$ & $\begin{array}{c}0.1539 \\
(0.1603)\end{array}$ & $\begin{array}{c}0.1860 \\
(0.1497)\end{array}$ \\
\hline hce_pub_texp & $\begin{array}{c}0.0708 \\
(0.0477)\end{array}$ & $\begin{array}{l}0.0781^{*} \\
(0.0422)\end{array}$ & $\begin{array}{c}0.0831 * * \\
(0.0330)\end{array}$ & $\begin{array}{l}0.0748^{*} \\
(0.0451)\end{array}$ & $\begin{array}{c}0.0948 * * * \\
(0.0319)\end{array}$ & $\begin{array}{c}0.0429 \\
(0.0941)\end{array}$ & $\begin{array}{c}0.0472 \\
(0.1055)\end{array}$ \\
\hline$h o s p \_b e d s \_g r$ & $\begin{array}{c}0.0426^{* *} \\
(0.0193)\end{array}$ & $\begin{array}{c}0.0393 * * \\
(0.0193)\end{array}$ & $\begin{array}{l}0.0365^{*} \\
(0.0189)\end{array}$ & $\begin{array}{c}0.0373 * * \\
(0.0177)\end{array}$ & $\begin{array}{c}0.0412 * * \\
(0.0206)\end{array}$ & $\begin{array}{l}0.0455^{*} \\
(0.0251)\end{array}$ & $\begin{array}{l}0.0357^{*} \\
(0.0199)\end{array}$ \\
\hline pollut_pop & $\begin{array}{c}0.0665^{* *} \\
(0.0305)\end{array}$ & $\begin{array}{c}0.0543 * * \\
(0.0249)\end{array}$ & $\begin{array}{l}0.0381 * \\
(0.0214)\end{array}$ & $\begin{array}{c}0.0535^{* *} \\
(0.0264)\end{array}$ & $\begin{array}{c}0.0035 \\
(0.0204)\end{array}$ & $\begin{array}{c}0.1956 \\
(0.1624)\end{array}$ & $\begin{array}{c}0.1975 * * \\
(0.0806)\end{array}$ \\
\hline trend & $\begin{array}{c}0.8063 * * * \\
(0.1359)\end{array}$ & $\begin{array}{c}0.7372 * * * \\
(0.1239)\end{array}$ & $\begin{array}{c}0.7123 * * * \\
(0.1056)\end{array}$ & $\begin{array}{c}0.7244 * * * \\
(0.1097)\end{array}$ & $\begin{array}{c}0.6665 * * * \\
(0.1055)\end{array}$ & $\begin{array}{c}0.6465 * * \\
(0.3293)\end{array}$ & $\begin{array}{c}0.6734 * * * \\
(0.1851)\end{array}$ \\
\hline \# Observations & 2024 & 2022 & 2019 & 2016 & 2012 & 1836 & 1987 \\
\hline \# Countries & 151 & 151 & 151 & 150 & 150 & 150 & 151 \\
\hline \# Instruments & 128 & 127 & 126 & 125 & 125 & 125 & \\
\hline $\mathrm{R}^{2}$ & & & & & & & 0.089 \\
\hline Hansen-test & 0.140 & 0.141 & 0.136 & 0.155 & 0.179 & 0.312 & \\
\hline Diff.-Hansen & 0.120 & 0.110 & 0.107 & 0.130 & 0.140 & & \\
\hline $\mathrm{AR}(1)$ & 0.000 & 0.000 & 0.000 & 0.000 & 0.000 & 0.000 & \\
\hline $\operatorname{AR}(2)$ & 0.319 & 0.301 & 0.349 & 0.320 & 0.336 & 0.247 & \\
\hline
\end{tabular}

Notes: See Table 1, 4 and 5, and the respective notes. A system-GMM estimator is used in regressions (1)-(5). In column (6) are shown the results from a difference-GMM estimator, while a fixed-effects estimator was used to obtain the results reported in column (7); robust standard errors are reported in parentheses. 
Table A.6. Robustness checks: regional areas

\begin{tabular}{|c|c|c|c|c|c|c|c|c|}
\hline & $\begin{array}{l}\text { OECD } \\
(1)\end{array}$ & $\begin{array}{c}\text { Non-OECD } \\
(2)\end{array}$ & $\begin{array}{c}\text { Europe } \\
\text { (3) }\end{array}$ & $\begin{array}{c}\text { Africa } \\
\text { (4) }\end{array}$ & $\begin{array}{c}\text { Asia } \\
(5)\end{array}$ & $\begin{array}{l}\text { NorthAm. } \\
\text { (6) }\end{array}$ & $\begin{array}{c}\text { SouthAm. } \\
\text { (7) }\end{array}$ & $\begin{array}{c}\text { Oceania } \\
(8)\end{array}$ \\
\hline L.rhcepc_gr & $\begin{array}{c}0.3054 * * * \\
(0.0443)\end{array}$ & $\begin{array}{l}0.0853^{*} \\
(0.0443)\end{array}$ & $\begin{array}{c}0.2773 * * * \\
(0.0424)\end{array}$ & & $\begin{array}{l}0.1185^{*} \\
(0.0592)\end{array}$ & & $\begin{array}{l}0.1699^{*} \\
(0.0857)\end{array}$ & \\
\hline sugar_swt_kcal & $\begin{array}{l}0.0312 * \\
(0.0184)\end{array}$ & $\begin{array}{c}0.0428 * * \\
(0.0186)\end{array}$ & $\begin{array}{c}0.0328^{*} \\
(0.0187)\end{array}$ & $\begin{array}{c}0.1114 * * \\
(0.0546)\end{array}$ & $\begin{array}{c}0.0008 \\
(0.0256)\end{array}$ & $\begin{array}{c}0.0486^{* *} \\
(0.0235)\end{array}$ & $\begin{array}{c}0.0144 \\
(0.0572)\end{array}$ & $\begin{array}{c}0.0183 \\
(0.0349)\end{array}$ \\
\hline$r g d p p c \_g r$ & $\begin{array}{c}1.2256 * * * \\
(0.2870)\end{array}$ & $\begin{array}{c}1.3430 * * * \\
(0.2091)\end{array}$ & $\begin{array}{c}1.5999 * * * \\
(0.2367)\end{array}$ & $\begin{array}{c}0.7315 * * \\
(0.3051)\end{array}$ & $\begin{array}{c}1.1177 * * * \\
(0.3428)\end{array}$ & $\begin{array}{c}0.5306 * * * \\
(0.1667)\end{array}$ & $\begin{array}{c}2.8369 * * * \\
(0.6581)\end{array}$ & $\begin{array}{c}0.0614 \\
(0.8544)\end{array}$ \\
\hline рор014 & $\begin{array}{c}2.1643 * * \\
(1.0586)\end{array}$ & $\begin{array}{c}0.2217 \\
(0.3678)\end{array}$ & $\begin{array}{c}1.4253^{*} \\
(0.8400)\end{array}$ & $\begin{array}{l}1.8778^{*} \\
(0.9988)\end{array}$ & $\begin{array}{c}0.0238 \\
(0.8588)\end{array}$ & $\begin{array}{l}-0.9166 \\
(0.6559)\end{array}$ & $\begin{array}{c}1.2987 \\
(2.3348)\end{array}$ & $\begin{array}{l}-5.2497 \\
(2.7649)\end{array}$ \\
\hline pop65abv & $\begin{array}{c}0.2027 \\
(0.8527)\end{array}$ & $\begin{array}{c}2.1307 \\
(1.2932)\end{array}$ & $\begin{array}{c}1.0048 \\
(1.2009)\end{array}$ & $\begin{array}{c}4.8607 \\
(4.7260)\end{array}$ & $\begin{array}{c}1.4529 \\
(2.2278)\end{array}$ & $\begin{array}{l}-2.2534 \\
(1.3564)\end{array}$ & $\begin{array}{c}9.3401 \\
(5.7887)\end{array}$ & $\begin{array}{c}12.8896^{*} \\
(5.3148)\end{array}$ \\
\hline urban_pop_ptot & $\begin{array}{c}0.5638 \\
(0.5036)\end{array}$ & $\begin{array}{c}0.3239 \\
(0.2663)\end{array}$ & $\begin{array}{c}0.4308 \\
(0.5728)\end{array}$ & $\begin{array}{c}1.3642 \\
(0.9648)\end{array}$ & $\begin{array}{l}-0.0569 \\
(0.7626)\end{array}$ & $\begin{array}{c}0.9027 * * * \\
(0.2195)\end{array}$ & $\begin{array}{c}-6.3945 * * * * \\
(1.4271)\end{array}$ & $\begin{array}{c}0.1122 \\
(2.8890)\end{array}$ \\
\hline lfp_female & $\begin{array}{c}0.0716 \\
(0.3126)\end{array}$ & $\begin{array}{l}-0.1859 \\
(0.2648)\end{array}$ & $\begin{array}{l}-0.3184 \\
(0.3252)\end{array}$ & $\begin{array}{c}-0.0290 \\
(0.6678)\end{array}$ & $\begin{array}{c}-0.6964 \\
(0.7180)\end{array}$ & $\begin{array}{l}0.4756^{*} \\
(0.2510)\end{array}$ & $\begin{array}{c}1.2379 \\
(1.1205)\end{array}$ & $\begin{array}{c}1.7370^{* *} \\
(0.5552)\end{array}$ \\
\hline hce_pub_texp & $\begin{array}{c}-0.2648^{*} \\
(0.1565)\end{array}$ & $\begin{array}{c}0.0129 \\
(0.0974)\end{array}$ & $\begin{array}{c}-0.4268^{*} \\
(0.2353)\end{array}$ & $\begin{array}{l}-0.0881 \\
(0.2549)\end{array}$ & $\begin{array}{c}0.0122 \\
(0.1026)\end{array}$ & $\begin{array}{c}-0.4297 * * * * \\
(0.1174)\end{array}$ & $\begin{array}{c}-0.0564 \\
(0.3643)\end{array}$ & $\begin{array}{l}1.3651^{\text {*** }} \\
(0.3813)\end{array}$ \\
\hline hosp_beds_gr & $\begin{array}{c}0.0280 \\
(0.0746)\end{array}$ & $\begin{array}{c}0.0070 \\
(0.0208)\end{array}$ & $\begin{array}{l}-0.1747 \\
(0.2200)\end{array}$ & $\begin{array}{c}0.0052 \\
(0.0395)\end{array}$ & $\begin{array}{c}0.0242 \\
(0.0371)\end{array}$ & $\begin{array}{l}-0.0370 \\
(0.0402)\end{array}$ & $\begin{array}{c}-0.0192 \\
(0.0450)\end{array}$ & $\begin{array}{l}-0.0366 \\
(0.1666)\end{array}$ \\
\hline pollut_pop & $\begin{array}{c}0.0457 \\
(0.0894)\end{array}$ & $\begin{array}{c}0.1501 \\
(0.0973)\end{array}$ & $\begin{array}{c}0.0232 \\
(0.1116)\end{array}$ & $\begin{array}{c}0.3723 * * * \\
(0.1375)\end{array}$ & $\begin{array}{c}0.0170 \\
(0.1961)\end{array}$ & $\begin{array}{l}-0.0682 \\
(0.0708)\end{array}$ & $\begin{array}{c}0.4897 * * \\
(0.2233)\end{array}$ & $\begin{array}{l}-0.1928 \\
(0.2593)\end{array}$ \\
\hline trend & $\begin{array}{c}0.0990 \\
(0.3646)\end{array}$ & $\begin{array}{c}0.6370 * * * \\
(0.2102)\end{array}$ & $\begin{array}{c}0.6068 \\
(0.3691)\end{array}$ & $\begin{array}{l}0.8339^{*} \\
(0.4631)\end{array}$ & $\begin{array}{c}0.9979 * * \\
(0.4749)\end{array}$ & $\begin{array}{c}-0.4204 \\
(0.2641)\end{array}$ & $\begin{array}{l}1.0187 \\
(0.8954)\end{array}$ & $\begin{array}{c}-0.2846 \\
(0.5911)\end{array}$ \\
\hline \# Obs & 481 & 1506 & 559 & 551 & & & 164 & 84 \\
\hline $\begin{array}{l}\text { \# Countries } \\
\mathrm{R}^{2}\end{array}$ & $\begin{array}{c}34 \\
0.286\end{array}$ & $\begin{array}{c}117 \\
0.167\end{array}$ & $\begin{array}{c}40 \\
0.304\end{array}$ & $\begin{array}{c}42 \\
0.0933\end{array}$ & $\begin{array}{c}33 \\
0.1705\end{array}$ & $\begin{array}{c}17 \\
0.1270\end{array}$ & $\begin{array}{c}13 \\
0.4231\end{array}$ & $\begin{array}{c}6 \\
0.1258\end{array}$ \\
\hline
\end{tabular}

Notes: See Table 1, 4, and 5, and the respective notes. A fixed-effects estimator was used to obtain the results reported in this table. Robust standard errors are reported in parentheses. 